\title{
Teorías marxistas del Estado y su aplicación al caso venezolano'
}

Recibido: 19/04/2018

Aprobado: 17/08/2018

\author{
STEVE ELLNER \\ Universidad de Oriente \\ sellner74@gmail.com
}

\begin{abstract}
RESUMEN
Las implicaciones de las teorías marxistas del Estado desarrolladas por Nicos Poulantzas, Louis Althusser y Ralph Miliband son útiles para enmarcar los asuntos básicos relacionados con la estrategia izquierdista en la Venezuela del siglo XXI. Existe una relación entre cada una de las teorías y tres problemas que confronta el movimiento chavista: i) si la burguesía (o fracciones de ella) exhibe un sentido de "conciencia de clase"; ii) la viabilidad de las alianzas tácticas y estratégicas entre la izquierda y los grupos vinculados a la estructura capitalista; iii) si el socialismo sería alcanzado por etapas, por cambios revolucionarios abruptos, o la radicalización continua del Estado durante un periodo extenso de tiempo. En la época en la cual Poulantzas escribió su concepto del Estado como un "campo de batalla estratégico", esto se prestó para la política de "alianzas estratégicas" de la izquierda con partidos ubicados a su derecha. El mismo concepto del Estado es compatible con el "proceso de cambio" en Venezuela en el que los movimientos autónomos desempeñan un papel fundamental en la transformación del viejo Estado y la construcción de nuevas estructuras estatales.
\end{abstract}

Palabras clave: Ralph Miliband, Louis Althusser, Nicos Poulantzas, Hugo Chávez, Fedecámaras, instrumentalismo, "revolución democrática nacional".

\section{Marxist theories of the State and their application to the Venezuela case}

\begin{abstract}
The implications of the Marxist theories of the State developed by Nicos Poulantzas, Louis Althusser and Ralph Miliband are useful in order to frame the basic elements related to the leftist strategy in Venezuela during the $21^{\text {st }}$ Century. There exists a relationship between each of these theories and three problems that Chavism faces: i) if the bourgeoise (or sectors of it) exhibit a sense of "class consciousness"; ii) the viability of tactical alliances and strategies between the left and groups associated to the capitalist structure; iii) if socialism can be achieved by phases, by abrupt revolutionary changes, or by the continuous radicalization of the State during an extensive period of time. At the time when Poulantzas wrote his concept of State as a "field of strategic battle", this lend itself to the politics of "strategic alliances" of the left with parties located in the right. The same concept of State is compatible with the "process of change" in Venezuela in which the autonomous movements develop a fundamental role in the transformation of the old State and the construction of new State structures.
\end{abstract}

Keywords: Ralph Miliband, Louis Althusser, Nicos Poulantzas, Hugo Chávez, Fedecámaras, instrumentalization, "democratic national revolution".

1 Artículo traducido por Giomar Salas, con el apoyo de José Gregorio Tovar y Eligio Damas. La revista Historical Materialism, 25(2), publicó una versión condensada de este artículo en inglés en el 2017. 
T a declaración de adhesión al socialismo hecha por Chávez en el 2005 desencadenó una discusión dentro de su movimiento y fuera de él sobre la naturaleza del Estado en la transición del sistema capitalista al socialista. Las teorías asociadas con Louis Althusser, Ralph Miliband y Nicos Poulantzas, que generaron entusiasmo entre las décadas de 1960 y 1970 y luego perdieron su atractivo en el apogeo del neoliberalismo, pero que desde entonces se han recuperado, ${ }^{2}$ sirven de cimientos para enmarcar los problemas y comprender el debate dentro del movimiento chavista, así como las diferentes vías y opciones que están siendo consideradas actualmente. El caso venezolano es instructivo por cuanto las condiciones de la nación para alcanzar el socialismo por vía democrática eran, en algunos aspectos, más propicias que las que enfrentaron los movimientos eurocomunistas, que inspiraron a Poulantzas y que fueron inspirados por él. De hecho, fueron indudablemente inigualables con cualquier otro país cuyo Gobierno haya estado comprometido con el socialismo democrático. Estas circunstancias hacen que el examen de las teorías marxistas del Estado contra el telón de fondo de los acontecimientos venezolanos sea de particular interés.

El siguiente trabajo examina la aplicabilidad de las tres teorías marxistas sobre el Estado: el instrumentalismo (asociado con Ralph Miliband), el marxismo estructural (asociado con Louis Althusser y Nicos Poulantzas) y la teoría relacional (asociada con Poulantzas). Una serie de intercambios entre Miliband y Poulantzas, entre 1969 y 1976, publicados en la revista New Left Review, arroja luz sobre el contraste entre el instrumentalismo y el marxismo estructural. Posteriormente, Poulantzas desarrolló una nueva teoría sobre el Estado que difería de manera fundamental de sus formulaciones anteriores. En aras de la claridad, me referiré a la etapa estructural marxista de Poulantzas como Poulantzas I y a la teoría relacional que desarrolló hacia el final de su vida como Poulantzas II.

El artículo discute las implicaciones de las tres teorías marxistas del Estado con respecto a las estrategias izquierdistas. Específicamente, postula una relación entre los tres puntos de vista sobre el Estado y tres temas que son básicos para entender el proceso de cambio en Venezuela: si la burguesía (o sectores de ella) manifiesta "conciencia de clase"; la viabilidad de las alianzas

2 Julian Müller (2009, p. 143) cita varios factores que explican el resurgimiento de interés en Poulantzas e incluye el ascenso al poder de gobiernos estatistas comprometidos con el socialismo en Venezuela y otras partes de América Latina, como también el rechazo al neoliberalismo como doctrina que minimiza el papel del Estado. 
tácticas o estratégicas forjadas por la izquierda con grupos políticos y económicos vinculados en mayor o menor grado con la estructura capitalista; y si el socialismo se alcanzará a través de una revolución en forma de un cambio abrupto, a través de etapas, o por un proceso continuo y relativamente prolongado de transformación del Estado.

El artículo es original por cuanto compara sistemáticamente las implicaciones políticas de las tres principales teorías marxistas sobre el Estado con respecto a tres asuntos de mayor trascendencia y luego aplica el análisis a un país específico. La metodología tiene lados positivos y negativos. En lo positivo, la aplicación de las teorías del Estado a condiciones tan profundamente diferentes de la Europa de las décadas de 1960 y 1970 realza la utilidad del debate intramarxista de esos años. Por otra parte, el análisis en base a las implicaciones es arriesgado en el sentido de que tal enfoque va más allá de las posiciones explícitas de los tres escritores, ninguno de los cuales abordó los tipos de desafíos que enfrentan los países del Tercer Mundo y la Venezuela del siglo XXI en particular.

El trabajo trata no solo del debate teórico, sino también aspectos específicos de la relación entre la estructura capitalista en Venezuela y el Gobierno chavista que estaba comprometido con una estrategia de movilización y lucha para lograr el socialismo. Las secciones del artículo examinan las relaciones conflictivas entre los chavistas gobernantes y los sectores empresariales, e incluyen un análisis sobre los intentos del Gobierno de privilegiar y promover el crecimiento de los empresarios "progresistas", así como su reacción con lo que se denominaba "la guerra económica" que resultaba en la escasez de los productos básicos, contrabando y acaparamiento. Estos conflictos forman parte del contexto para la discusión de los asuntos de la "conciencia de clase" de la burguesía (definida como la defensa activa de los intereses sistémicos a largo plazo, además de sus intereses estrictamente económicos), la "conciencia de clase" de la supuestamente amigable "burguesía productiva" o emergente, y la relación entre el Estado y la estructura capitalista. El análisis se relaciona directamente con las teorías sobre el Estado desarrolladas por Miliband, Althusser y Poulantzas en un contexto político radicalmente diferente al de Venezuela en el siglo XXI.

El tema fundamental para la izquierda venezolana que emerge del artículo, y tiene una importancia primordial para el momento de su finalización en el 2015, es el papel del Gobierno del presidente Maduro en contribuir al logro del socialismo. De hecho, muchos en la izquierda se están haciendo las siguientes 
preguntas que son pertinentes al artículo: ¿Se han reforzado los vínculos entre el Estado y la estructura capitalista debido a las alianzas con las empresas y la corrupción institucionalizada como para descartar la posibilidad de pasos en la dirección del socialismo? ¿Los reveses sufridos en años recientes por el chavismo demuestran que la serie de pequeñas "rupturas revolucionarias" que ocurrieron bajo Chávez — un proceso contemplado por Poulantzas como sustituto por la toma del poder por la fuerza - eran insuficientes para allanar el camino al socialismo? ¿O puede el "viejo Estado”, encabezado por los chavistas, desempeñar un papel complementario o contribuyente, junto con los movimientos sociales y la base del partido chavista, en profundizar el proceso de cambio, de acuerdo con el pensamiento de Poulantzas II? El artículo no pretende proporcionar respuestas a estas preguntas. Su principal afirmación es que las teorías marxistas sobre el Estado ayudan a enmarcar asuntos polémicos fundamentales y así contribuyen a la clarificación de las complejas y desafiantes experiencias del chavismo en Venezuela.

\section{Las posiciones de las teorías marxistas del Estado sobre tres asuntos fundamentales relacionados con la estrategia socialista}

El enfoque comparativo del artículo se enfrenta a un obstáculo central. Cada una de las tres teorías marxistas sobre el Estado ha sido interpretada de maneras diferentes con implicaciones distintas para el análisis del mismo y la estrategia izquierdista. Esta diversidad se complica aún más por las modificaciones en el pensamiento de Althusser, Poulantzas y (aunque en menor medida) Miliband en el transcurso de periodos de tiempo relativamente cortos. ${ }^{3} \mathrm{La}$ proliferación de interpretaciones amenaza con socavar la utilidad de las tres teorías como puntos de referencia para enmarcar los asuntos claves concernientes al Estado, las clases sociales y la estrategia política.

Para cada una de las tres teorías sobre el Estado analizadas en este artículo, he elegido la línea de pensamiento marxista que parece ser predominante

3 El pensamiento de Miliband evolucionó de manera significativa después de la publicación de su libro The State in Capitalist Society. En el transcurso de su debate con Poulantzas, rechazó la etiqueta de "instrumentalista" y en Marxism and Politics incorporó el estructuralismo en su análisis del Estado (Miliband 1977, pp. 72-74). Althusser y Poutlantzas también negaron ser estructuralistas mientras que William Domhoff negó ser instrumentalista. Althusser, con su fórmula "Estado = Represión e Ideología" difiere de Poulantzas quien desde el principio hizo énfasis en el papel del Estado en reducir la intensidad del conflicto de clases en el frente económico. 
y que al mismo tiempo agudiza los contrastes en concordancia con el objetivo básico de este artículo. El instrumentalismo se definirá de acuerdo con el "instrumentalismo duro", que minimiza la autonomía del Estado, un enfoque que no coincide completamente con los trabajos de Miliband (Barrow, 1993, p. 13). En gran medida, el "instrumentalismo duro" difiere de la escuela del instrumentalismo de los no marxistas que centra su análisis en la influencia desproporcionada de los capitalistas en la formulación de políticas, pero deja fuera de juego sus esfuerzos por defender el sistema capitalista como tal (ver, por ejemplo, Domhoff, 1990, pp. 2-5). Al hacerlo así, ignoran "la conciencia de clase" de los capitalistas, una característica que es clave para el pensamiento de los instrumentalistas marxistas, como se demuestra en el artículo.

De manera similar, mi discusión sobre el marxismo estructural se basa en el "estructuralismo duro". Esta corriente destaca la lógica económica inflexible del capitalismo, e incluye los imperativos del mercado, que se encuentran en los escritos de Poulantzas I. Más que Althusser, Poulantzas se interesaba por las funciones económicas del Estado, ${ }^{4}$ en contraposición con las versiones "más blandas" del estructuralismo representadas por Fred Block, quien preveía el espacio considerable para las maniobras del Estado (Barrow, 1993, p. 62).

A pesar de las objeciones a la identificación de Miliband con el "instrumentalismo duro", y de Poulantzas y Althusser con el "estructuralismo duro", ambas formulaciones teóricas son útiles para comprender el debate izquierdista en Venezuela. No solo el instrumentalismo y el estructuralismo, tal como se definen en este artículo, estaban bien representados entre los izquierdistas venezolanos, sino ambos modelos arrojan luz sobre las relaciones entre cada uno de los tres temas que se discutirán más adelante.

Las subsecciones siguientes explican la relación entre cada una de las tres teorías y sus posiciones sobre los tres temas críticos en el contexto de los países desarrollados, particularmente Europa de la década de 1970. La discusión de las tres teorías sobre el Estado ayuda a suministrar una perspectiva más amplia para los temas polémicos que el artículo analizará luego en el contexto venezolano: la estrategia de alianzas diseñada por los izquierdistas con las

$4 \quad$ El argumento marxista estructural de que el Estado está ligado a la lógica del capitalismo, que incluye la dinámica de la acumulación del capital, en algunos casos va más allá de los imperativos del mercado (como, por ejemplo, evitar los aumentos salariales sustanciales) destacados por los neoliberales. Como señala Block (1977, p. 16) en su discusión de la "confianza empresarial", las condiciones del mercado (bajos salarios, por ejemplo) no dictan necesariamente las decisiones de inversión. 
fuerzas ubicadas a su derecha, la conciencia de clases de la burguesía y la naturaleza de la transición al socialismo.

\subsection{Instrumentalismo marxista: rechazo de alianzas con los partidos socialdemócratas y sectores de la burguesía}

Los instrumentalistas marxistas argumentan que el papel básico del Estado es defender los intereses de la clase capitalista, aunque no distinguen entre los intereses inmediatos y los de largo plazo. Más que cualquier otro escrito, citan la célebre frase del Manifiesto comunista de que "el órgano ejecutivo del Estado moderno no es más que un comité para gestionar los asuntos comunes de toda la burguesía". Los instrumentalistas interpretan este planteamiento como una afirmación de que el Estado representa un "comité ejecutivo o un instrumento directo de la clase gobernante” (Jessop, 2002). La interpretación implica un nexo estrecho y simple entre el Estado y la clase capitalista y ha sido defendida por las corrientes de la "izquierda dura", que incluyen a los marxistas ortodoxos, los trotskistas y los anarquistas. Los instrumentalistas marxistas y no marxistas (como William Domhoff) intentan demostrar el comportamiento consistentemente proempresarial del Estado al documentar los numerosos vínculos que existen entre quienes poseen el poder político y el poder económico. Ejemplos de ello son las contribuciones a las campañas electorales y los círculos exclusivos que incorporan tanto a las élites políticas como a las económicas, como también los clubes sociales y los foros diseñados para formular la política gubernamental. En resumen, la función del Estado es mantener los intereses de la burguesía y lo hace debido a sus intrincados lazos con la clase capitalista.

$\mathrm{Al}$ analizar las relaciones entre la estructura capitalista y el Estado, hay que distinguir entre las formas personales y conscientes de control por parte de la burguesía, por una parte, y los mecanismos naturales generados por las condiciones del mercado, por otra. La desinversión en respuesta a las políticas gubernamentales percibidas como adversas a los intereses del sector privado puede ser el resultado de una campaña emprendida por grupos empresariales con fines políticos, o de la falta de incentivos para invertir. Los instrumentalistas resaltan lo primero y concluyen que la burguesía tiene conciencia de clase y es relativamente cohesionada. ${ }^{5}$ En general, el punto de partida del pensa-

$5 \quad$ Miliband (1969, p. 48) escribió que las élites económicas en las naciones capitalistas avanzadas poseen "un alto grado de cohesión y solidaridad con intereses y propósitos comunes que trascienden sus diferencias específicas". Fred Block (1977, p. 10) criticó esta noción y afirmó que Marx también la cuestionó. 
miento instrumentalista es la cohesión y la conciencia de clase de la burguesía que, en consecuencia, es capaz de ejercer una influencia directa e inigualable sobre el Estado a un grado no reconocido por el marxismo estructural.

Este artículo se centra principalmente en el "instrumentalismo duro" que enfatiza la tenacidad de los vínculos entre las élites económicas y políticas. La vinculación cruza el Estado en muchos niveles y no solo en la cúpula. Como resultado, el "instrumentalismo duro" o "crudo" tiende a minimizar el potencial del Estado para hacer valer un grado importante de autonomía, una posición defendida por Paul Sweezy (1942, p. 243), por ejemplo, cuando lo llamó "un instrumento en las manos de la clase dominante para hacer cumplir y garantizar la estabilidad de la estructura de clase". En contraste con los "instrumentalistas duros", Miliband (1977, p. 83) criticó a muchos marxistas por subestimar la autonomía del Estado, aunque criticó a Marx y a Engels por sobreestimarla.

Marx y Engels abordaron el asunto de la autonomía del Estado en su análisis de los regímenes que eran independientes de la burguesía, aunque servían a sus intereses de clase (particularmente el fenómeno del bonapartismo representado por Luis Napoleón Bonaparte). En el siglo XX, la discusión marxista de situaciones de una pronunciada afirmación de la autonomía del Estado se enfocó en gran medida en los gobiernos de partidos socialdemócratas (como también los gobiernos fascistas), cuya base social era la pequeña burguesía y sectores de la clase obrera (Block, 1977, pp. 17-19; Miliband, 1969, pp. 96-118). Si bien no hay nada incompatible entre el instrumentalismo y el reconocimiento de que los gobiernos socialdemócratas pueden alcanzar mayor autonomía que los gobiernos conservadores, los instrumentalistas manifiestan cierto grado de escepticismo. Miliband (1969, p. 111), por ejemplo, señaló que la administración pública del Gobierno del Partido Laborista británico después de la Segunda Guerra Mundial estaba conformada "precisamente por los mismos funcionarios burócratas que habían servido a sus predecesores", mientras que los "asesores oficiales" del pasado también desempeñaron un papel clave. No obstante, Miliband no llegó al extremo de caracterizar el Estado como territorio enemigo ni a oponerse a cualquier estrategia de trabajar dentro de él para alcanzar los objetivos izquierdistas. Reconoció que, a nivel local, los funcionarios elegidos de la clase media socialdemócrata "ciertamente pueden hacer mucho a favor de los votantes de la clase obrera", aunque agregó que en estos municipios los obreros carecen de participación directa (Miliband, 1969, pp. 177-178). 
Los acontecimientos políticos que se iniciaron en la década de 1980 bajo la influencia del neoliberalismo han favorecido la tesis instrumentalista y las estrategias asociadas con ella. En primer lugar, en los países capitalistas avanzados, el giro general del establishment político hacia la derecha ha conducido a lo que un periodista llamó "la muerte de la clase liberal" (Hedges, 2010). Esta tendencia pone en duda la capacidad del Estado de distanciarse de la estructura capitalista y la viabilidad de las estrategias de apoyo de la izquierda para los políticos prosistema. Un segundo factor que parece demostrar la "conciencia de clase" de los capitalistas de acuerdo con la tesis instrumentalista sería los vínculos flagrantes entre las élites políticas y económicas que sobrepasan los documentados por Domhoff (1990), Mills (1956, pp. 165-170), Lundberg (1968, pp. 889-934) y otros en la era posguerra. En los Estados Unidos, la decisión Ciudadanos Unidos en el 2010 de la Corte Suprema abrió más las compuertas de grandes cantidades de dinero en la política, mientras que dos años más tarde el número de congresistas multimillonarios representó por primera vez una mayoría en el Congreso. En tercer lugar, Miliband (1969, pp. 125-126) señaló el reciente surgimiento de "una nueva generación de tecnócratas" que no pertenecen "exclusivamente al mundo del Gobierno ni al mundo empresarial", y como resultado "los límites entre estos dos mundos son cada vez más borrosos e imperceptibles”. El desplazamiento de los funcionarios profesionales apolíticos formados en la tradición weberiana reforzó el vínculo personal y tangible entre el sector privado y el Estado de acuerdo con el análisis instrumentalista. La privatización de muchos servicios gubernamentales que incluyen el servicio de inteligencia y el Ejército fortalece aún más estos vínculos.

Los observadores generalmente coincidieron en que Poulantzas le ganó el debate a Miliband, cuyas posiciones se prestaban a las estrategias ubicadas más a la izquierda en el espectro político y que percibieron el Estado como menos autónomo que lo previsto por los marxistas estructurales (Block, 1977, p. 9; Althusser y Balibar, 1970, pp. 216-218). Sin embargo, las recientes tendencias mencionadas indicarían que lo que aquí se llama el "instrumentalismo duro" tiene mayor relevancia en la política actual que en el pasado y la aceptación de sus argumentos y línea de pensamiento no se limita a una franja marginal ultraizquierdista (Block, 1980, p. 236). Mientras que el debate teórico ha ido más allá del "instrumentalismo duro" al reconocer generalmente un grado significativo de autonomía del Estado y especificidad (ver Block, 1977, pp. 8-9), los análisis políticos de la izquierda y otros han documentado los 
vínculos cada vez más tenaces entre las élites políticas y económicas para explicar los desarrollos políticos en la era del neoliberalismo y la globalización.

Para determinar las implicaciones de la posición instrumentalista para la estrategia de alianzas, hay que distinguir entre los socialdemócratas moderados que carecen de compromiso con cambios estructurales profundos y los socialdemócratas radicales. Los últimos se identifican con un líder carismático con una capacidad considerable de movilizar los seguidores. El líder tiende a ser un outsider que antes de llegar a ser presidente a menudo se niega a aliarse o tener tratos con los que están cerca del poder. Los ejemplos en América Latina incluyen a Fidel Castro cuando llegó al poder en 1959 y Jorge Eliécer Gaitán en Colombia en el momento de su asesinato en 1948. Ambos fueron radicales que, sin embargo, habían chocado con el Partido Comunista y habían manifestado posiciones socialdemócratas, apartándose públicamente de la izquierda. Otro ejemplo es Hugo Chávez, un outsider quien en el momento de su elección en 1998 explícitamente abrazó la noción de la "tercera vía" asociada con Anthony Giddens (Raby, 2006, pp. 99, 112-116, 157).

Los instrumentalistas, incluidos los "duros", pudieran haber reconocido el potencial revolucionario de Gaitán en 1948, Castro en 1959 y Chávez en 1998, y anticipado la autonomía del Estado frente a la estructura capitalista en esos países. Por lo tanto, los instrumentalistas de izquierda no habrían descartado la posibilidad de alianzas con esos tres líderes. Al mismo tiempo, sin embargo, los instrumentalistas consideran que los gobiernos socialdemócratas moderados están tan intrincadamente vinculados a la estructura de poder que no merecen el apoyo izquierdista de ningún tipo. En consecuencia, el "instrumentalismo duro" es adverso a las alianzas tácticas o estratégicas con los socialdemócratas moderados y en los Estados Unidos descartaría el respaldo de, o los entendimientos con, los políticos del Partido Demócrata.

\subsection{Marxismo estructural: apoyo a las alianzas tácticas}

Lo escrito por Miliband ofrecía una explicación empírica de lo que el marxismo siempre ha mantenido: que la estructura capitalista está inextricablemente vinculada a la superestructura del Estado. En contraste, el marxismo estructural representaba una tesis original para explicar por qué el capitalismo ha demostrado ser tan resistente como para haber sobrevivido a las crisis políticas y económicas (como en 1918 y en la década de 1930) que muchos izquierdistas para ese momento presumieron significaba el colapso del sis- 
tema. ${ }^{6}$ Los marxistas estructurales argumentaban que la función primordial del Estado es garantizar la estabilidad del sistema y su supervivencia a largo plazo. Para este propósito, el Estado media entre los intereses de la burguesía y la clase obrera y regula, en vez de intentar eliminar, el conflicto de clases. En el proceso, el Estado muestra un grado de autonomía en el frente económico a través de la implementación de reformas - como hace en el frente ideológico, en contraste con el aparato represivo (Althusser, 1971, p. 147; Poulantzas, 1969, p. 78) - El concepto de autonomía relativa del Estado fue reforzado por la teoría de sobredeterminación de Althusser en la que la multiplicidad de relaciones entre los componentes de la estructura y la superestructura confiere a la última (en este caso, el Estado) un grado de autonomía. Poulantzas, más que Miliband, reconocía el estatus semiautónomo del Estado y no solamente bajo las circunstancias anormales del régimen bonapartista, fascista o socialdemócrata, sino como una característica normal de cualquier Gobierno democrático(Jessop, 2002, pp. 179-194).

Sin embargo, Poulantzas, Althusser y otros marxistas estructurales reconocieron (al igual que Marx) que para cumplir su función de garantizar la supervivencia del capitalismo, el Estado facilita la reproducción de las relaciones de producción y la acumulación del capital. Para Poulantzas, en particular, "el funcionamiento de los mercados... encarcela la toma de decisiones" (Barrow, 1993, p. 62). La misma lógica del sistema obliga al Estado a privilegiar los intereses económicos de la burguesía (aunque no necesariamente los del corto plazo), ya que un clima de inversión favorable asegura la “confianza empresarial” y así estimula la acumulación de capital (ver Block, 1977, pp. 14-19). En resumen, a pesar de las limitaciones bien definidas, el Estado mantiene un grado de autonomía frente a la estructura capitalista en materia de política económica, al mismo tiempo que es inflexible en su defensa de los intereses a largo plazo y la supervivencia del capitalismo.

El concepto marxista estructural del papel y las funciones del Estado tiene implicaciones para la estrategia izquierdista. La autonomía relativa del Estado en materia económica, como lo planteó Poulantzas I y otros, se presta a la priorización de los objetivos reformistas de la izquierda (Block, 1977, pp. 12-13) que incluyen las alianzas tácticas con partidos moderados y el respaldo ocasional de candidatos moderados. Sin embargo, el vínculo indi-

$6 \quad$ Althusser destacó la importancia de la tendencia del capitalismo a reproducir las condiciones y relaciones de producción. Esta dinámica ayuda a explicar la habilidad del capitalismo para renovarse e inventarse frente a las crisis profundas. 
soluble entre el Estado y la estructura capitalista que el marxismo estructural prevé ( $\mathrm{y}$ en cierta forma es aún más vinculante que en el concepto del Estado formulado por el instrumentalismo) excluiría las alianzas de naturaleza estratégica por parte de la izquierda con moderados que tienen vínculos con sectores de la burguesía.

Las experiencias de los partidos comunistas de Francia (PCF) y de los Estados Unidos (CPUSA) en sus relaciones con los partidos ubicados a su derecha sirven para ilustrar la diferencia entre alianzas "estratégicas", por una parte, y alianzas y apoyo tácticos, por la otra, y su importancia con respecto a la teoría del Estado del marxismo estructural. Si bien las alianzas estratégicas son duraderas y se basan en una serie de denominadores comunes básicos, las alianzas tácticas son frágiles y tienen menos probabilidades de sobrevivir a la prueba del tiempo.

La teoría marxista estructural del Estado contemplaba la viabilidad de reformas económicas sin alterar la estructura del sistema capitalista y así se prestó para la alianza táctica del PCF con el Partido Socialista francés fundamentada en una plataforma reformista. Al igual que el Partido Laborista británico de la posguerra analizado por Miliband, el Partido Socialista rechazó una ruptura completa con el capitalismo y tuvo vínculos con la élite económica. Las relaciones tempestuosas entre el PCF y los socialistas en la década de 1970 culminaron en las elecciones presidenciales de 1981 cuando las críticas del candidato del PCF George Marchais contra el candidato socialista Francois Mitterand fueron, al menos al principio, casi tan intensas como las que formulaba contra sus rivales conservadores. En la segunda vuelta, sin embargo, los comunistas se aliaron con los socialistas, quienes salieron victoriosos. Dada su mutua desconfianza, la alianza del Partido Socialista y el PCF, conocida como el Programa Común, no podía llamarse "estratégica", al menos por la definición dada por este artículo.

La diferencia entre las alianzas estratégicas y tácticas con respecto a las relaciones comunista-socialistas era un asunto importante de contención dentro del PCF, del cual Althusser era miembro activo y Poulantzas, como residente francés, siguió de cerca. El Frente Popular contra el fascismo, que por cierto se originó en Francia en 1934, sirvió como un punto de referencia en la discusión durante las décadas de 1960 y 1970. La experiencia del Frente Popular fue un contrapeso al dogmatismo asociado con el estalinismo, contra el cual los escritos de Althusser hasta un cierto punto representaron una reacción. De hecho, Althusser fue considerado influyente en la iniciación de la discusión dentro del 
PCF sobre las relaciones interpartidistas (Lewis, 2007, p. 177). Althusser mantuvo el liderazgo del PCF en gran estima (a pesar de algunas diferencias bien publicitadas entre los dos) y así no rompió con el partido en la década de 1960, cuando él parecía estar más cerca de las posiciones chinas, y terminó aceptando la condena que hacía el partido a su crítica de la ideología (Ferretter, 2006, pp. 69-70). Ese respeto terminó en el momento del enfrentamiento comunistasocialista en 1978 y de sus propias reformulaciones teóricas.

Althusser, aunque apoyaba las alianzas con los partidos moderados, advirtió de sus limitaciones y peligros. En este sentido, compartía la desconfianza general de los líderes del PCF hacia el Partido Socialista y estuvo de acuerdo con la promoción de lo que se llama en este artículo una "alianza táctica" entre los dos partidos. En la década de 1960, la insistencia de Althusser en la predominancia de la "estructura" sobre la "superestructura" chocó con el marxismo humanista (representado por Roger Garaudy), que era considerado más compatible con la proposición de forjar una alianza estratégica con los socialistas. De hecho, algunos líderes del PCF temían que las posiciones de Althusser pondrían en peligro la "política de unidad" del partido (Lewis, 2007, pp. 140-143). En Note on the ISAs, publicado en 1970, Althusser argumentaba que los revolucionarios que hacen alianzas con los moderados terminan "muy frecuentemente subordinados a ellos". Además, "participando en el juego, [ellos] son absorbidos por el juego, y abandonan la lucha de clases en favor de la colaboración de clases". Concluye que "un partido comunista no tiene por qué entrar al Gobierno de un Estado burgués... para "administrar [sus] asuntos", ya que su papel es "ampliar el alcance de la lucha de clases y prepararse para la caída del Estado burgués”. En este sentido, el Partido Comunista es un "“partido de nuevo tipo', completamente diferente de los partidos burgueses" (Althusser, 2014). Estas posiciones sobre el partido, que fueron la consecuencia lógica de la teoría estructural del Estado, pueden ayudar a explicar por qué el PCF no fue capaz de mantener relaciones de trabajo sólidas con el Partido Socialista y de desarrollar una alianza verdaderamente "estratégica" para alcanzar metas a largo plazo.

Otro ejemplo de apoyo "táctico", en contraste del apoyo "estratégico" a los partidos moderados, es la posición histórica del Partido Comunista de los Estados Unidos (CPUSA) hacia el ala liberal del Partido Demócrata que se remonta al New Deal en la década de 1930. El CPUSA mostró preferencia por los demócratas moderados y liberales (y particularmente políticos afroamericanos) sobre sus rivales republicanos. Al hacerlo, generalmente descartó la 
posición de "dos males en el mismo saco" (o "dos caimanes del mismo pozo") que minimizaba las diferencias entre los demócratas y los republicanos.

La política de "apoyo táctico" del CPUSA contrastaba con las dos otras posiciones defendidas por algunos líderes comunistas. Por un lado, la política de repudio total al Partido Demócrata fue reforzada por la tesis instrumentalista sobre los intrincados lazos entre los partidos proestablishment y los intereses capitalistas. Por otra parte, el apoyo duradero de los comunistas a los demócratas liberales (o una estrategia de trabajar dentro del Partido Demócrata) sugirió un intento de forjar una relación "estratégica". Así, por ejemplo, el secretario general del CPUSA, Earl Browder, quien promovió las posiciones pro New Deal en la década de 1930, terminó proponiendo la disolución del Partido Comunista para facilitar la convergencia con los demócratas de acuerdo con la estrategia de la "alianza estratégica" (Isserman, 1987, pp. 5-6). William Z. Foster, quien había criticado a Browder desde la izquierda durante estos años, lo reemplazó en la dirección del CPUSA y promovió la candidatura presidencial independiente de Henry Wallace en 1948, en oposición a lo que los líderes comunistas de la época llamaron el "sistema bipartidista controlado por Wall Street". El apoyo a Wallace, que algunos comunistas posteriormente consideraron un error que ayudó a preparar el terreno para el macartismo (al identificar y aislar a los comunistas y sus aliados dentro del movimiento sindical y en otros frentes), compaginaba con el pensamiento instrumentalista de rechazo a los pactos con partidos políticos del establishment. Aunque en años posteriores los principales líderes del CPUSA respaldaron ocasionalmente a los candidatos demócratas y generalmente favorecieron el Partido Demócrata sobre el Partido Republicano, rechazaron la propuesta de los miembros críticos del partido como Dorothy Healey de desarrollar relaciones de trabajo más estrechas o "estratégicas" con los demócratas liberales. Healey (1993, pp. 206-207), por ejemplo, a finales de la década de 1960, criticó a los líderes del CPUSA por subestimar el potencial de los demócratas liberales como Eugene McCarthy (un precandidato presidencial en 1968), de quien algunos izquierdistas, más hacia la izquierda, afirmaban tenía la intención de cooptar el movimiento popular.

\subsection{La tesis relacional de Poulantzas: apoyo a las alianzas estratégicas}

En State, Power, Socialism y otros trabajos publicados poco antes de su muerte prematura en 1979, Poulantzas añadió otro elemento al marxismo estructural 
que había defendido anteriormente. Según Poulantzas II, la estructura capitalista no es solamente una relación de dominio, sino una relación de lucha de clases, una dimensión que tiene que reflejarse en la superestructura del Estado. Así, Poulantzas afirmó que "las luchas populares atraviesan el Estado de arriba hacia abajo y en un modo bastante distinto de la penetración de una entidad intrínseca desde el exterior". En el mismo trabajo mantuvo que el Estado es "la condensación de las relaciones de clase" y "un campo estratégico de batalla" en el que los diversos grupos sociales hacen valer su presencia. Así que la influencia de los sectores populares va más allá de la mera presión externa de los grupos de interés (Poulantzas, 1978, p. 141). Poulantzas (1978, pp. 152, 259) incluso negó la naturaleza monolítica del aparato represivo. Al mismo tiempo, sin embargo, reconoció que la estructura capitalista "en última instancia" (una frase usada frecuentemente por Althusser) es el elemento decisivo. Decir lo contrario sería ver al Estado como un "sujeto" y dotarlo con "autonomía absoluta”, como hacen, según Poulantzas (1979, p. 198; 1978, pp. 129, 131), los socialdemócratas — contrario al principio marxista fundamental del vínculo permanente entre la estructura y la superestructura.

La teoría del Estado y las relaciones de clase de Poulantzas II se prestaron para las alianzas estratégicas entre los socialistas izquierdistas y los socialdemócratas y otros moderados políticos. En primer lugar, el Estado era más maleable e inestable - debido en gran parte a los choques entre las fracciones de la burguesía - que lo previsto por los instrumentalistas y marxistas estructurales. Así, cualquier alianza exitosa abría la posibilidad de un proceso continuo de su transformación en tándem con los avances izquierdistas en los frentes políticos y culturales. En segundo lugar, la visión de Poulantzas II de una "etapa larga" consistente de una serie de "rupturas revolucionarias" previas al logro definitivo del socialismo implicaba la factibilidad de alianzas estratégicas con grupos sociales y políticos a la derecha del Partido Comunista. Según Poulantzas II, este proceso contrasta con el escenario de un "gran día" cuando la revolución ocurra en la forma de una batalla final con la participación de solo los más comprometidos con la causa socialista (Poulantzas, 1978, pp. 129,$131 ; 1979$, p. 198). De la misma manera en la cual el intento del Estado burgués en mantener la hegemonía y garantizar la estabilidad del sistema a largo plazo implica una estrategia de alianzas, como planteó Gramsci, los izquierdistas en el poder también necesitan forjar un nuevo bloque histórico basado en alianzas estratégicas. 
En tercer lugar, Poulantzas II definió la clase obrera solamente como aquellos obreros ubicados en el sector industrial y al mismo tiempo clasificó gran parte de la fuerza laboral que no produce plusvalía (o "asalariados no productivos") como "clase media" (Poulantzas, 1975, p. 204). Esta conceptualización lo llevó a solicitar a la izquierda comunista que fuera más allá de una política de concesiones a una estrategia a largo plazo de ganar a la clase media mediante el reconocimiento de la legitimidad de sus diferencias con el proletariado y que viera a ellas como "diferencias entre el pueblo" (Jessop, 1982, pp. 168-169). En pocas palabras, las relaciones de clase contempladas por Poulantzas II apuntalaban una alianza estratégica de base amplia que incluía a las clases obreras y medias, así como ciertas fracciones de la burguesía.

Poulantzas aplicó sus formulaciones teóricas a la situación política concreta en Europa al abogar por alianzas estratégicas de los partidos comunistas con los partidos socialdemócratas a su derecha. Estos acuerdos iban a ser más incluyentes que las alianzas tácticas implícitas en el marxismo estructural, y que, como señaló Poulantzas II, irían más allá de los pactos electorales nacionales para incluir las convergencias a nivel de las clases populares y las organizaciones sociales (Poulantzas, 1979, p. 195). Criticó al PCF por no promover la unidad integral y agregó que solamente una reorganización del partido le permitiría superar el dogmatismo y el sectarismo que socavaba la cooperación con los socialistas.

\section{El papel del Estado en la transformación socialista en Venezuela}

La teoría del Estado de Poulantzas II, a diferencia del estructuralismo de Poulantzas I y el "instrumentalismo duro", era optimista sobre la posibilidad de transformar el viejo Estado inmerso en el sistema capitalista en un agente del socialismo, específicamente en el caso de la Europa de la década de 1970 (Poulantzas, 1978, p. 257). El pensamiento de Poulantzas sirvió para justificar la estrategia eurocomunista de formar alianzas estratégicas con los partidos socialdemócratas a su derecha con el propósito de ganar el poder a través de elecciones y lograr cambios de gran alcance. Al defender esta estrategia, Poulantzas (1979, p. 195) fue alentado por la crisis estructural del capitalismo que se produjo durante la década de 1970.

Las condiciones en Venezuela desde la llegada de Chávez al poder han sido, en varios aspectos importantes, más favorables para la transformación 
conducida por el Estado que las de Italia, España, Grecia y otras naciones donde el eurocomunismo tuvo una presencia importante en la década de 1970. De hecho, esta condición propicia pareció excluir la necesidad del tipo de alianzas estratégicas con los partidos políticamente moderados promovidas por los eurocomunistas. La aplicabilidad de Poulantzas II a Venezuela fue señalada en el prominente blog marxista "Lenin's Tomb", en un análisis de State, Power, Socialism: "Tal vez el único lugar donde se ha implementado algo como esta estrategia [la de Poulantzas] y producido algunos resultados —no el socialismo, por supuesto- es el caso sumamente excepcional de Venezuela donde la lucha de las clases populares ha atravesado hasta la cúspide sin ningún revés serio todavía en vista (¿Poulantzas como un coautor del "Socialismo del siglo XXI"?). Pero creo que si los planteamientos superiores de Poulantzas son tomados en serio, su lógica es revolucionaria" (Seymour, 2012).

\subsection{El contexto: la estructura capitalista de Venezuela y el camino democrático al socialismo}

Varios rasgos distintivos del Gobierno chavista realzaron las posibilidades de lograr el socialismo democrático dirigido por el Estado en Venezuela y tienen implicaciones importantes para el debate entre los instrumentalistas y Poulantzas. En primer lugar, después de los intentos de derrocar a Chávez en el 2002-2003, el Ejecutivo nacional ganó el control de las dos instituciones más importantes de la nación: las Fuerzas Armadas y la compañía petrolera estatal PDVSA. En ambos casos, los partidarios del Gobierno de Chávez reemplazaron a los miembros principales de la institución que habían participado abiertamente en el movimiento insurreccional. En segundo lugar, el boom de los precios petroleros a nivel mundial proporcionó al Gobierno recursos para pagar las expropiaciones en industrias estratégicas y la implementación de programas sociales que promovieron el empoderamiento de los sectores marginados de la población.

Finalmente, los adversarios del Gobierno de izquierda estaban en una posición particularmente débil como resultado de los golpes recibidos tanto antes como después de 1998. Así, por ejemplo, el impacto desastroso de las políticas neoliberales de los años noventa desacreditó a los partidos políticos proestablishment. Además, la penetración en sectores de la economía por parte de las multinacionales a finales de las décadas de 1980 y 1990 fue más 
extensa que en otras partes del continente, y debilitó al sector privado venezolano, que estaba envuelto en una intensa rivalidad interna durante esos años (Ortiz, 2004, pp. 79-82). Del mismo modo, a principios del siglo XXI se observó la disminución de la influencia continental de los Estados Unidos, como lo demuestra la derrota de la propuesta del Área de Libre Comercio de las Américas (ALCA) en el 2005 y el surgimiento de organizaciones latinoamericanas unificadas que rivalizaron con la Organización de Estados Americanos (OEA), tradicionalmente dominada por Washington.

Conjuntamente con estos factores favorables que alimentaron la retórica ferviente de Chávez y el optimismo de su movimiento, hubo otros que apuntaron en la dirección opuesta. En primer lugar, Venezuela carecía de los movimientos sociales bien organizados que allanaran el camino para el ascenso al poder de los izquierdistas y centroizquierdistas en otras partes de la región. En segundo lugar, como productor de petróleo, Venezuela era más dependiente de su recurso bandera que sus vecinos y, por lo tanto, era particularmente susceptible a fuertes fluctuaciones de ingresos, al mismo tiempo que su base productiva industrial era más frágil. Además, la economía rentista de Venezuela creó un sentimiento de paternalismo entre los venezolanos de todas las clases que presumían que era obligación del Estado atender a todas sus necesidades (Coronil, 2002, pp. 251-384). Finalmente, los economistas marxistas destacaron la ilusión generalizada de que con el surgimiento de gobiernos proizquierdistas en la América Latina del siglo XXI, el socialismo era una siguiente etapa fácil, cuando en realidad el capitalismo global estaba más atrincherado que nunca (Katz, 2015).

Además, el Estado venezolano no estaba del todo divorciado de la estructura capitalista dominada por grupos económicos poderosos que eran agresivamente opuestos al Gobierno chavista. El intento de golpe contra Chávez en abril del 2002 y los dos meses de huelga general del 2002-2003 (en efecto, un cierre patronal) hicieron mucho para definir la relación entre el Gobierno y el sector privado. La principal organización empresarial Fedecámaras dirigió ambos intentos para cambiar el régimen y de hecho su presidente, Pedro Carmona, fue presidente provisional de Venezuela por dos días como resultado del golpe. Aunque la huelga general (así como el golpe) fue derrotada como consecuencia de la movilización de los sectores populares, la cooperación de algunos empresarios con el Gobierno, particularmente en el área de transporte, fue decisiva al suministrar gran parte de los bienes de consumo general durante el conflicto. Este grupo de empresarios antigolpe consistía 
de aquellos que hasta cierto punto eran simpatizantes chavistas, al igual que antichavistas, que rechazaron el llamado a huelga por razones profesionales u oportunistas.

Independientemente de su motivación, los empresarios antihuelgas naturalmente fueron considerados por el Gobierno más confiables que los miembros de Fedecámaras que siguieron en su línea. Posteriormente, el liderazgo chavista siguió una política no oficial de otorgar trato preferencial a los empresarios antihuelgas y, en efecto, los privilegió en el otorgamiento de contratos de obras públicas y crédito estatal. El 4 de febrero del 2003, Chávez anunció: "Les trancamos la llave a los golpistas, ni un dólar más para ellos". Al mismo tiempo instruyó al jefe del recién creado CADIVI (el sistema para la venta de "dólares preferenciales" a los importadores a una tasa de cambio artificialmente baja) a rechazar las solicitudes de divisas por parte de los empresarios comerciales que habían apoyado la huelga general. ${ }^{7}$ Posteriormente, los portavoces de Fedecámaras acusaron al Gobierno de promover estructuras empresariales paralelas.

La política de discriminación del Gobierno contra los empresarios de Fedecámaras fue una respuesta lógica a la actividad disruptiva e insurreccional de la organización que contrastaba con su discreción política anterior y su afirmación (ciertamente engañosa) de ser apolítica, que se remontaba a su fundación en 1944 (Ellner, 2014, p. 151). Al seguir esta estrategia, sin embargo, el liderazgo chavista descartó el argumento de que el Gobierno debería mantener la transparencia por encima de todas las consideraciones políticas y por lo tanto abstenerse de mostrar preferencia por ningún empresario o grupo económico en particular. La estrategia del Gobierno favoreció a un grupo de pequeños y medianos empresarios, algunos de los cuales eran de origen árabe, a expensas de la burguesía tradicional, que formaba la columna vertebral de Fedecámaras y mantenía vínculos con los Estados Unidos y Europa a través de nexos económicos, educativos y familiares. La élite económica emergente comenzó con poco capital y en algunos casos acumuló una riqueza significativa durante la presidencia de Chávez. Bajo los gobiernos chavistas, incursionaron en el área de las importaciones y proyectos de obras públicas locales, de los que tuvieron un desempeño relativo, pero no lograron desarrollar una capacidad financiera e industrial viable o el grado de competitividad para llevar a cabo megaproyectos. Como resultado de lo anterior, para muchos de los

$7 \quad$ El Universal, febrero del 2003. 
proyectos de gran escala y complejos, el Gobierno cambió de los socios tradicionales a otros nuevos en el extranjero. La compañía brasileña Odebrecht, por ejemplo, recibió contratos para una diversidad de obras que incluyeron megaproyectos como la construcción de dos puentes sobre el río Orinoco, la expansión del metro de Caracas, los sistemas ferroviarios y un terminal de carga de tanqueros petroleros costa afuera en José Anzoátegui. En otros casos, el Gobierno se vio en la necesidad de restablecer las relaciones de trabajo con las empresas venezolanas tradicionales.

La estrategia chavista tuvo más éxito en el frente político - al menos en el corto plazo- que en el económico. Un ejemplo de los empresarios prochavistas es Miguel Pérez Abad, quien pertenece al Partido Socialista Unido de Venezuela (PSUV) y ha tenido aspiraciones políticas. Pérez Abad encabezaba la organización empresarial Fedeindustria, que articula los intereses de los pequeños y medianos empresarios. Él y otros empresarios prochavistas defendían las políticas del Gobierno de abrir oportunidades para los empresarios, particularmente con la aceptación de Venezuela como miembro con plenos derechos de Mercosur (que se consideró un logro chavista importante). Los empresarios prochavistas argumentaban que el Gobierno había logrado aumentar la producción, pero también el poder adquisitivo de la gente, por lo que era imperativo simplificar las tramitaciones burocráticas para facilitar las importaciones que tanto se necesitaban. También asistían regularmente a reuniones y asambleas convocadas por Chávez, y luego por Maduro, con el fin de dirigirse a los miembros del sector privado (Bilbao, 2008, p. 196).

No obstante, la política de favorecer a los empresarios prochavistas no logró el objetivo de estimular altos niveles de producción e inclusive resultó propicio para actividades de dudosa legalidad. Estas consecuencias decepcionantes fueron evidenciadas por la crisis financiera del 2009, cuando el Gobierno expropió más de trece instituciones financieras, encarceló por lo menos a ocho banqueros y ordenó el arresto de otros cuarenta más que huyeron del país. Entre los banqueros estaban varios que con poco dinero se hicieron ricos aprovechándose de la determinación del Gobierno de esquivar a la burguesía tradicional y depositar su dinero en nuevas instituciones financieras. Uno de ellos, Arné Chacón, era el hermano de un importante ministro chavista (ambos habían participado en la intentona de golpe de noviembre de 1992 apoyado por Chávez), que como resultado renunció a su cargo. Otro fue el empresario del transporte, hasta ese momento relativamente desconocido, Ricardo Fernández Barrueco, cuya fortuna se estimaba en más de un millardo 
de dólares y cuyas principales empresas fueron expropiadas como resultado del escándalo. Tanto Chacón como Fernández pasaron tres años en prisión a partir de diciembre del 2009.

Un segundo escándalo, que aparentemente involucró a la burguesía emergente, estalló en el 2013 cuando dos altos funcionarios gubernamentales anunciaron que el año anterior CADIVI había vendido cerca de 20 mil millones de dólares a la tasa preferencial para el propósito de pagar solicitudes de importaciones falsas. Al igual que en el 2009, algunos (aunque no todos) de los implicados, evidentemente, tenían estrechas relaciones de trabajo con el Gobierno chavista.

La aguda escasez del 2013-2015 demostró que la estrategia del Gobierno para estimular la producción no dejó los resultados deseados. Las cooperativas de trabajadores promovidas por el Gobierno y "las compañías de producción social", así como las empresas recientemente expropiadas, particularmente en el sector alimentario, no suministraron la cantidad suficiente de bienes para llenar los vacíos creados por la escasez. Del mismo modo, los resultados de la estrategia del Gobierno de fomentar el crecimiento de nuevas empresas que pertenecían a los llamados "empresarios productivos" estuvieron muy por debajo de las expectativas.

Además, los miembros de la burguesía emergente que habían recibido respaldo gubernamental no siempre resultaron ser aliados confiables. Un ejemplo notable fue Alberto Cudemus, que había demitido de Fedecámaras en el 2007, después de dos intentos infructuosos por llegar a su presidencia sobre una plataforma de mantener relaciones amistosas con el Gobierno chavista y oponerse a la politización de la organización. Como el comerciante de porcinos más grande de la nación y el presidente de la Federación Venezolana de Porcicultura (Feporcina), Cudemus recibió contratos para abastecer a la empresa estatal de alimentos Mercal de acuerdo con la política de apoyo a la burguesía "productiva" no tradicional. Sin embargo, para el año 2014, Cudemus criticó la legislación emblemática de Maduro, la Ley de Precios Justos, como un "retroceso a los conceptos de los años sesenta", y atribuyó el déficit de producción de la nación en parte a la Ley Orgánica del Trabajo (LOTTT) del 2012 que Maduro había ayudado a redactar. Maduro respondió atacándolo, como también al presidente de Fedecámaras Jorge Roig, quienes coincidieron en su análisis de la crisis y los pasos necesarios para superarla.

El desempeño del Gobierno de Maduro en contrarrestar la especulación de precios, el acaparamiento, el contrabando y la corrupción tuvo aspectos 
positivos y negativos. Por una parte, su falta de reacción inmediata y decisiva en el caso de Cadivi contrastaba con la firmeza de la respuesta de Chávez a la crisis financiera del 2009. También contrastaba con la bandera principal del movimiento chavista desde su comienzo, que era la lucha frontal contra la corrupción. Por otra parte, encarceló a unas doscientas personas acusadas de corrupción en el 2013, entre ellas varios líderes chavistas de nivel medio. En otra medida sin precedentes, Maduro aprobó la Ley de Precios Justos, que definió la especulación de precios como la ganancia superior al 30\% del costo. $\mathrm{Su}$ reconocimiento de la posible existencia de una "boliburguesía" (empresarios "chavistas" que acumularon una riqueza significativa sobre la base de un pequeño capital original) demostró que por lo menos reconoció el peligro del desarrollo de un "capitalismo de compadres", aun cuando las medidas tomadas para frenar ese desarrollo eran generalmente tímidas.

A partir de finales del 2013, el Gobierno declaró la guerra contra la especulación y el acaparamiento, con inspecciones que resultaron en tomas temporales de empresas, confiscación de mercancía, procedimientos judiciales y el encarcelamiento de más de cien gerentes de empresas. No obstante, al año siguiente, el presidente Maduro evidentemente aceptó la insistencia de Fedecámaras en que la aplicación de los castigos penales fuese consecuencia de procedimientos judiciales, con toda la lentitud que ese proceso implicaba, y que antes de llegar a un veredicto en los tribunales, el Gobierno debería abstenerse de hacer público los detalles del caso.

Las reuniones de alto nivel entre el Ejecutivo y miembros de la burguesía tradicional y no tradicional a principios del 2014 indicaron un giro en la política y estrategia en ambos lados. Las reuniones, que formaban parte de un "diálogo de paz" con los sectores organizados de la población, fueron diseñadas para hallar solución a los problemas de escasez, especulación y acaparamiento, y también poner coto a las protestas disruptivas promovidas por la oposición que estallaron en febrero del 2014. La posición más conciliadora del Gobierno hacia Fedecámaras, y su promesa de no discriminar contra la misma, representó un reconocimiento de que la burguesía emergente era incapaz de desarrollarse en una fuerza dinámica para reemplazar los grupos empresariales tradicionales. Fedecámaras, por su parte, aceptó la participación en el diálogo a pesar de que los partidos de oposición la rechazaron, en marcado contraste con la alianza político-empresarial destinada a derrocar al Gobierno en el 2002-2003. La decisión de Fedecámaras de aceptar la invitación de Maduro para reunirse en el palacio presidencial fue también un 
reconocimiento de que sus miembros habían sido afectados gravemente por la política preferencial del Gobierno hacia la burguesía emergente.

La anterior discusión esclarece los vínculos que existen entre el Estado y la estructura capitalista en Venezuela, a pesar del compromiso socialista de los que estaban en el poder y la aguda polarización que contrapuso el sector empresarial tradicional contra el Gobierno chavista. Varios temas planteados en este artículo sobre las teorías marxistas del Estado son subyacentes a la relación entre los chavistas y los grupos empresariales. Específicamente, el debate sobre si los problemas de escasez, especulación de precios, acaparamiento y contrabando fueron inducidos por razones políticas, o se debieron a las condiciones del mercado, arroja luces sobre la conciencia de clases, la cohesión y la fragmentación de la clase capitalista venezolana (tema 1 en las tablas 1, 2 y 3). Las siguientes secciones también están relacionadas con las diferentes estrategias defendidas por los izquierdistas venezolanos (temas $2 \mathrm{y}$ 3 en las tablas 1, 2 y 3), y el debate teórico concomitante.

\section{2. "Conciencia de clase" y la teoría de la "burguesía progresista" aplicada al caso venezolano}

El tema de la conciencia de clase de la burguesía, que ayudó a definir las diferencias entre el instrumentalismo y el marxismo estructural, tiene un significado especial para la política izquierdista latinoamericana del último siglo. Para el instrumentalismo, la burguesía defiende activamente sus intereses, tanto los de corto como los de largo plazo. En un ejemplo de esta perspectiva, los comunistas latinoamericanos y otros izquierdistas tradicionalmente postulaban que la burguesía industrial "progresista" tiene una visión hacia el futuro y es capaz de resistir la presión proveniente de la derecha anticomunista. Según la izquierda tradicional, la burguesía, o un sector de ella, lejos de situarse al margen, participa activamente en la política en función de sus intereses estructurales. La siguiente subsección discutirá la experiencia de la izquierda latinoamericana con la estrategia hacia los "empresarios progresistas" y su aplicación al caso venezolano, y luego sacará conclusiones en base de las teorías marxistas del Estado.

El concepto de la "revolución democrática nacional", promovida por la Tercera Internacional (el Comintern) entre las dos guerras mundiales, preveía la existencia de una burguesía industrial que desempeñara un papel directo en la lucha contra el imperialismo al aliarse con organizaciones obreras y parti- 
dos de la izquierda. Del mismo modo, el intento del Gobierno chavista de promover una alianza con la burguesía emergente de Venezuela, que rechazaría la presión de los poderosos intereses económicos tradicionales encabezados por Fedecámaras, también presuponía una conciencia de clase avanzada y un grado de audacia que recordaba los esquemas antiimperialistas del siglo XX. En ambos casos, la estrategia se apoyaba en un vínculo directo entre los capitalistas y un Estado progresista.

La vinculación tangible entre los capitalistas y el Estado se puso de manifiesto en la estrategia defendida por Luis Miquilena, la mano derecha de Chávez durante los primeros años de su presidencia. Miquilena había sido un miembro importante del movimiento comunista en la década de 1940, y luego de dimitir, desarrolló estrechos vínculos con empresarios fuera de la burguesía tradicional. Como secretario de finanzas del movimiento chavista, Miquilena obtuvo grandes sumas de dinero para la campaña presidencial de 1998 provenientes de los empresarios, y luego como ministro del Interior cultivó relaciones cercanas con algunos de ellos. En discusiones internas, Miquilena apoyó la incorporación de miembros "honestos" de la burguesía en el movimiento, al mismo tiempo que propuso (junto con sus aliados chavistas) la privatización del sistema de salud y advirtió contra las reformas radicales, incluyendo la retroactividad de las prestaciones sociales.

Miquilena estuvo influenciado por la estrategia de dos etapas, defendida durante mucho tiempo por los partidos comunistas de América Latina. ${ }^{8}$ Según este enfoque, una "burguesía nacional progresista" concentrada en el sector industrial —en contraposición a las esferas comercial y financiera- desempeñaba un papel activo en el logro de objetivos nacionalistas e incluso antiimperialistas antes de iniciar la lucha por el socialismo. La estrategia contemplaba una alianza estratégica entre la izquierda y esta burguesía progresista. El concepto sustentó el frentismo popular en la década de 1930 y la formación de alianzas en décadas posteriores (Miquilena, 2000).

La tesis de la "burguesía progresista" parecía comprobar la aplicabilidad en los países en desarrollo de la perspectiva que enfatiza la influencia tangible de la clase capitalista sobre el Estado en favor de sus intereses sistémicos a largo plazo. La estrategia comunista — en concordancia con esta línea— con-

8 Miquilena fue miembro destacado de un grupo comunista disidente en la década de 1940 que era relativamente escéptico del potencial de transformación de la burguesía nacional venezolana (aunque sin rechazar el concepto de la "burguesía nacional progresista" a nivel teórico), pero posteriormente modificó su posición sobre el asunto (Ellner 1980, pp. 146-164). 
templaba una vinculación entre una fracción de clase de la burguesía que estaba consciente de sus intereses a largo plazo y un movimiento de base amplia que iba a alcanzar el poder por medios electorales. No obstante, durante el periodo de sustitución de importaciones y nacionalismo económico en América Latina, tales vínculos fueron históricamente frágiles, como fue demostrado por las relaciones "ambiguas" entre los industriales argentinos y el Gobierno de Juan Domingo Perón en las décadas de 1940 y 1950 (Collier y Collier, 1991, p. 333). ${ }^{9}$ En el caso de Venezuela, el Partido Comunista (PCV) apoyó a varios gobiernos progresistas desde 1941 hasta 1948, cuando promovieron la intervención del Estado en la economía. No obstante, el único ejemplo de una presencia marcada de un miembro de la burguesía industrial fue el periodo de dos años de Eduardo Mendoza Goiticoa (hermano del magnate del cemento Eugenio Mendoza) como ministro de Agricultura bajo el Gobierno de Rómulo Betancourt.

Teniendo en cuenta el curso completo de la historia latinoamericana del siglo XX hasta el inicio de la globalización en la década de 1980, es evidente que los comunistas exageraron cuando plantearon la existencia de una "burguesía nacional progresista". La burguesía industrial difícilmente pudiera considerarse antiimperialista, ni cumplía con el papel de una fracción de clase que era políticamente enérgica, decidida y consciente de sus intereses a largo plazo, según lo sugerido por la tesis instrumentalista. Esta deficiencia, sin embargo, no descarta la existencia de una burguesía que - contrario a las afirmaciones de muchos en la extrema izquierda - ocasionalmente adoptaban posiciones, aunque tímidamente, que apuntan en la dirección del desarrollo nacional autónomo. Mientras la burguesía nacional se abstuvo de respaldar el nacionalismo económico como bandera, sus puntos de vista generalmente iban de la oposición leve al apoyo pasivo a los gobiernos que perseguían esas políticas.

En las últimas décadas, la izquierda latinoamericana ha abandonado en gran parte la tesis de la "burguesía nacional". No obstante, la tendencia a diferenciar entre la "buena" y la "mala" burguesía continuó manifestándose dentro del movimiento chavista después de la deserción de Miquilena en el momento del golpe de abril del 2002. Las corrientes moderadas dentro del partido chavista, inicialmente dirigidas por Miquilena, insisten en que hay sectores de la burguesía que son "honestos" y "productivos", aunque se abstienen de etiquetarlos "antiimperialistas", o inclusive "progresistas". El pre-

9 Las credenciales antiimperialistas de Perón eran más fuertes que las de otros presidentes progresistas de la época, ya que nacionalizó los ferrocarriles de propiedad británica y la compañía telefónica de la ITT. 
sidente Maduro ocasionalmente empleaba el término "empresarios productivos" para referirse al sector industrial privado.

La directora de formación ideológica del partido chavista, Aurora Morales, señaló que después de la salida de Miquilena los chavistas rechazaron su visión de un movimiento multiclasista que incorporaría empresarios representantes de la burguesía productiva (Morales, 2004). Añadió que la priorización de los sectores populares por parte del Gobierno de Chávez, basándose en que son los que más necesitan el apoyo estatal, excluía el concepto de un partido multiclasista que incluyera representantes de la élite. Cuando el partido chavista se declaró oficialmente socialista en el 2005, y dos años más tarde se convirtió en el Partido Socialista Unido de Venezuela (PSUV), en efecto, descartó una participación directa de los capitalistas en la toma de decisiones del partido.

Sin embargo, la relación precisa entre el partido chavista y el Gobierno, por un lado, y sus aliados del sector privado, por el otro, sigue siendo poco clara. Dentro del movimiento chavista hubo poca discusión sobre el tema. Sin embargo, es un hecho conocido que algunos chavistas elegidos a cargos a nivel local están asociados con empresas de construcción que reciben contratos para realizar obras públicas. Una práctica relacionada, que no ha sido suficientemente denunciada y no se ha debatido, es el procedimiento notorio heredado del periodo anterior a Chávez de cobrar a las empresas constructoras un porcentaje del valor de cada contrato de obras públicas que se otorgan. El caso de Cadivi sugiere que estos vínculos son significativos. El presidente Maduro contribuyó a la credibilidad de las acusaciones sobre relaciones comerciales, poco éticas, cuando reconoció la posible existencia de una "boliburguesía”, un término usado por los antichavistas y también los de la izquierda más radical (Rangel, 2006).

Un segundo ámbito de ambigüedad es la falta de precisión en cuanto al papel que los pequeños y medianos empresarios deben desempeñar en la construcción del socialismo en Venezuela. La espinosa cuestión de si un partido comprometido con el socialismo puede considerarlos aliados y de cómo distinguir empíricamente entre medianos y grandes capitalistas nunca se ha abordado seriamente en el movimiento chavista. La posición del PSUV sobre estos asuntos claves inevitablemente influenciaría las relaciones entre el Gobierno chavista y el sector privado.

En resumen, los gobiernos chavistas desarrollaron vínculos tangibles con la burguesía emergente, a pesar de que ese sector no resultó progresista, parti- 
cularmente confiable, ni productivo. La naturaleza de los vínculos se ve obscurecida por la falta de debate dentro del movimiento chavista respecto al papel que se espera que el sector privado desempeñe en el proceso de cambio. Estas relaciones indican que incluso en las naciones capitalistas cuyos gobiernos están comprometidos con el socialismo, los vínculos estrechos y continuos con el sector privado surgen, a menudo, como el resultado no anticipado de la estrategia del Gobierno para contrarrestar las amenazas insurgentes de la derecha apoyada por los grupos empresariales tradicionales.

La infructuosa experiencia de los chavistas con la clase empresarial emergente y la experiencia histórica de la estrategia de la izquierda latinoamericana de la "revolución democrática nacional" son instructivas por lo que revelan sobre la "conciencia de clase" de la burguesía. Lo más resaltante en el caso del esquema de la "revolución democrática nacional" es que los que la implementaron no lograron el apoyo activo de la misma fracción de clase que más iba a beneficiase por la estrategia del nacionalismo económico. En el caso de Venezuela, Chávez ofreció a los empresarios emergentes una oportunidad de oro para reemplazar a la burguesía tradicional, pero su desempeño decepcionante forzó al Gobierno de Maduro a reconsiderar la estrategia y negociar con Fedecámaras.

En América Latina, la conciencia de clase de la burguesía - y específicamente en referencia a la defensa de sus intereses a largo plazo - implica una estrategia audaz de alianzas con sectores populares diseñada para combatir la penetración de las empresas multinacionales. Históricamente, sin embargo, la burguesía industrial se ha quedado corta en cuanto al esfuerzo de lograr estos objetivos. En el caso de Venezuela, la bifurcación entre la burguesía tradicional y la burguesía emergente no puso en evidencia la conciencia de clase de esta última que era incapaz de, o no quería, desplazar a la primera, aprovechándose del apoyo del Gobierno para promover el desarrollo económico autónomo. Por otra parte, la fragmentación de clase (básica para el análisis de Poulantzas II) desempeñó un papel político importante cuando la burguesía emergente ayudó a apuntalar al Gobierno chavista frente a una oposición agresiva. En resumen, las posiciones teóricas del instrumentalismo y Poulantzas sobre la conciencia de clase de la burguesía y las fracciones de clase son pertinentes para entender los desafíos claves que han enfrentado los gobiernos chavistas. 


\subsection{Marcos teóricos para entender los problemas económicos que enfrentan los gobiernos chavistas: instrumentalismo vs. estructuralismo}

Los activistas y analistas de izquierda han presentado dos explicaciones básicas de los principales problemas económicos que han enfrentado los gobiernos chavistas. El problema más apremiante era la escasez de productos básicos, que se remonta a la huelga general del 2002-2003. Inmediatamente después del conflicto, el Gobierno intentó afrontar sus efectos adversos mediante la aplicación del sistema de control de cambio y de precios, lo que a su vez desencadenó actividades ilícitas, específicamente especulación, acaparamiento y contrabando. Según una explicación, propia del pensamiento instrumentalista sobre la conciencia de clase de la burguesía, los problemas fueron inducidos para abrir el camino al cambio del régimen. En el primer caso de "guerra económica" contra el Gobierno, Fedecámaras encabezó la huelga general del 2002-2003 que virtualmente paralizó la producción y en el proceso amenazó con desencadenar una inflación desenfrenada. El próximo caso de escasez aguda fue durante los meses previos al referéndum nacional sobre la propuesta de reforma constitucional del 2007, que el sector privado consideraba una amenaza peligrosa. El sector empresarial, según la primera explicación, intensificó la guerra económica tras la muerte de Chávez en el 2013 para aprovecharse de una crisis anticipada en el liderazgo chavista. El presidente Maduro y los líderes chavistas a finales del 2013 usaron frecuentemente el término "guerra económica", lo cual implicaba que la crisis fue inducida por razones políticas. De manera similar, las corrientes izquierdistas del PSUV tendieron a enfocarse exclusivamente en las motivaciones políticas de lo que ellos llamaban una "situación provocada". ${ }^{10}$ La explicación política se fundamentaba en la perspectiva instrumentalista que veía al sector privado consciente de sus intereses y dispuesto a actuar agresivamente como un bloque poderoso para defender su condición hegemónica.

10 Para el 2014, Marea Socialista (MS) había surgido como el grupo izquierdista más grande dentro del PSUV. Fue fundado a principios del 2007 como una división de una corriente dirigida por los trotskistas dentro del movimiento obrero producida como resultado del debate sobre la propuesta de ingresar en el recién fundado PSUV. Algunos de sus miembros (pero no todos) se identificaron con el trotskismo. Cuando la crisis económica se profundizó en el 2015, MS endureció su posición contra Maduro. La mayoría de los líderes de MS, que incluyeron a Gonzalo Gómez y Nicmer Evans (quien salió de la MR en el 2017), reconocieron la existencia de una guerra económica conscientemente promovida por el sector empresarial, pero argumentaron que el término estaba siendo usado por Maduro para no enfrentar problemas como la fuga de capital y la corrupción, y abogaron por la nacionalización de la banca y el comercio exterior. 
Los chavistas también presentaron una segunda explicación de los problemas económicos de la nación que estaba en línea con el marxismo estructural, con su énfasis en la lógica económica del capitalismo que incluye las exigencias del mercado, en contraposición a la influencia personal y política de los capitalistas. Según este punto de vista, las distorsiones del mercado llegaron a un extremo en un periodo corto entre el 2012 y 2013, cuando la disparidad entre la tasa de cambio del mercado abierto y la oficial pasó de dos a uno a casi diez a uno. El resultado previsible fue no solamente la escasez, el contrabando, el acaparamiento y la especulación de precios, sino también la corrupción a medida que la disparidad creciente entre el cambio oficial y nooficial de la moneda aumentó los beneficios que se derivaban de la actividad económica ilícita. Aquellos que dieron mayor peso a la segunda explicación tendieron a pertenecer a una corriente chavista moderada, que hacía hincapié en los resultados positivos del diálogo con el sector privado y atribuía las dificultades económicas de la nación, en gran parte, a las políticas fiscales que necesitaban ser reformuladas.

Los partidarios de la segunda explicación favorecían la modificación o el levantamiento de los controles cambiarios y de precios para atraer inversiones con el propósito de estimular las exportaciones a los países de Mercosur y otras partes de América Latina. Los moderados concluyeron que la debacle de la escasez del 2013-2015 demostró que los socialistas necesitan tomar en serio las condiciones del mercado, aunque su estrategia es eventualmente eliminarlo. Los moderados también cuestionaron la plausibilidad de la "teoría de la conspiración", asociada con el instrumentalismo (aunque negado por algunos instrumentalistas; Domhoff, 1990, pp. 69, 187), que acusaba a los capitalistas de perpetrar sabotaje económico. El exministro y economista chavista Víctor Álvarez, por ejemplo, que abogó por un sistema de bandas que permitiera que la tasa de cambio se aproximara siempre al valor real del bolívar, argumentó que "el problema fundamental que confronta Venezuela es económico" y que el principal desafío que enfrenta el Gobierno era el diseño de políticas técnicamente sólidas para reemplazar la economía rentista. ${ }^{11}$ Óscar Schemel (2014), un analista de opinión pública cercano al chavismo, fue más específico cuando afirmó que "ni el imperialismo estadounidense ni la oligarquía deben ser chivos expiatorios, ya que lo que se necesita es un enfoque más racional de la economía para superar la escasez que enfrentamos".

11 El Nacional, 29 de junio del 2014. 
Ambos factores que explican la escasez están en juego en formas importantes: el incentivo económico para vender mercancías en el mercado negro o mediante el contrabando debido a la gran disparidad entre los precios oficiales y los no oficiales; y el motivo político para debilitar el Gobierno chavista. La primera motivación corresponde al enfoque marxista estructural sobre la lógica económica del sistema capitalista, mientras que la segunda coincide con el argumento instrumentalista respecto al comportamiento político consciente de clase de los capitalistas. Las dos teorías difieren en cuanto a cuál de los dos factores constituyen "en última instancia" la explicación fundamental.

Las dos explicaciones, sin embargo, pueden ser complementarias, en cuyo caso determinar cuál es la más "fundamental" se convierte en un punto difícil de determinar. Así, por ejemplo, la desestabilización económica se hizo más intensa en los periodos de conflicto político agudo, específicamente la huelga general del 2002-2003, los meses antes del referéndum sobre la propuesta de reforma constitucional, y el periodo posterior a la muerte de Chávez en el 2013-2014. Estas secuencias dieron credibilidad a la tesis del sabotaje económico motivado políticamente (perspectiva instrumentalista). Sin embargo, una vez que los productos básicos se hicieron escasos, la especulación de precios, el acaparamiento y el contrabando obedecieron a la lógica del mercado (perspectiva marxista estructural), ya que el aumento de incentivos para la actividad ilícita desafió la capacidad de la burocracia del Estado de hacer cumplir la ley e implementar correctivos.

En otro ejemplo de interacción entre las dos dinámicas, la actividad insurgente de la oposición en el 2002-2003 y las protestas perturbadoras del 2014 y 2017 influyeron en el Gobierno para llevar a cabo políticas populistas para garantizar el apoyo popular, lo que se consideró un imperativo en momentos de peligro político inminente. Específicamente, las protestas obligaron al Gobierno a mantener los precios regulados muy por debajo del valor del mercado, fomentando así el surgimiento de un mercado negro y socavando las empresas recién expropiadas que no podían cubrir los costos de producción. Por lo tanto, la desinversión por razones políticas (de acuerdo con el enfoque instrumentalista) creó desajustes en el mercado antes de los cuales el Gobierno fue reacio a corregir a través de políticas de austeridad, consciente del precio político que tendría que pagar.

En estos casos, una vez que el conflicto político fue superado, los líderes chavistas no podían culpar a la oposición por la persistencia de las dificultades económicas. Las medidas técnicamente sólidas destinadas a corregir 
los desequilibrios creados por el sector privado. y por la movilización de las fuerzas de oposición, corrieron el riesgo de producir una inflación desenfrenada y una reacción peligrosamente adversa en la población. Así, la resistencia política por parte de la burguesía a un Gobierno de izquierda genera una serie de distorsiones económicas a largo plazo que tienen una lógica propia después de que la amenaza política disminuye. ${ }^{12}$ Esta dinámica que combina una oposición política despiadada y distorsiones extremas del mercado representa un reto desafiante para la construcción socialista. De hecho, explica en gran medida los dilemas básicos del socialismo del siglo XX, como el fracaso en lograr un despegue en la producción de bienes de consumo

\subsection{Las estrategias para lograr el socialismo y el debate sobre el Estado venezolano}

Las teorías sobre el Estado aplicadas a Venezuela tienen implicaciones distintas en cuanto a la estrategia y el análisis izquierdistas. Específicamente, apoyan diferentes posiciones sobre dos temas que se discutirán a continuación: la viabilidad de alianzas con el sector empresarial; y la caracterización de la transición socialista, bien sea por etapas o por un "proceso" continuo de transformación. Como indican las tablas 1, 2 y 3, los términos de debate para el análisis del Estado desde una perspectiva marxista difieren entre la Europa de la década de 1970 y la Venezuela chavista. El contraste es particularmente pronunciado en el caso de Poulantzas II, mientras que las implicaciones del instrumentalismo son básicamente las mismas en el contexto europeo y el venezolano.

\subsection{El enfoque instrumentalista}

Los analistas y activistas izquierdistas han aplicado la tesis instrumentalista sobre los vínculos tangibles y personales entre la estructura capitalista y el Estado a Venezuela bajo el Gobierno chavista, tal como Miliband y otros lo

12 Los motivos de los capitalistas que no invierten por considerar el Gobierno hostil a sus intereses son difíciles de determinar. La especulación de precios y el contrabando que generan ganancias inmediatas pueden ser atribuidos a motivos económicos más que políticos. Pero el caso de inversiones ambiciosas y costosas es menos sencillo. La decisión de no invertir puede ser el resultado de un cálculo simple costo-beneficio o puede ser políticamente conducida con el objetivo de generar inestabilidad, bien sea para influenciar políticas económicas específicas, o para promover el cambio de régimen. Las diferencias entre estos motivos pueden ser obscuras y en todo caso difíciles de documentar. 
hicieron en el contexto de Europa y los Estados Unidos, como se describió en la primera sección de este artículo. Aquellos que escriben en la tradición instrumentalista señalan que los vínculos de los líderes chavistas con la burguesía emergente constituyen una relación excesivamente estrecha que impide una mayor radicalización. El análisis instrumentalista señala las múltiples formas en las que los empresarios, llamados a veces la "boliburguesía", han penetrado la esfera del Estado a través de conexiones legítimas e ilegítimas. Un ejemplo de esto último es la notoria vieja práctica que ha continuado en el Gobierno chavista del pago de comisiones por las obras públicas.

\section{Tabla 1}

LAS POSICIONES DE LA TEORÍA INSTRUMENTALISTA SOBRE TEMAS CRÍTICOS

EN DOS CONTEXTOS DISTINTOS

\begin{tabular}{ccc}
\hline Tres temas críticos & $\begin{array}{c}\text { Posiciones izquierdistas en las } \\
\text { naciones desarrolladas bajo } \\
\text { circunstancias normales }\end{array}$ & $\begin{array}{c}\text { Posiciones izquierdistas en la } \\
\text { Venezuela chavista }\end{array}$ \\
\hline
\end{tabular}

Tema 1: Conciencia de La burguesía es en gran parte coclase de la burguesía o hesiva y tiene conciencia de clase sectores de ella

Tema 2: Formación de Rechazo de las alianzas con los alianzas

Tema 3: Naturaleza de la transición al socialismo movimientos y los partidos con vínculos en los asientos del poder

La revolución ocurre mediante una ruptura (o rupturas) radical definitiva con el pasado; apoya el concepto de "poder dual" de Lenin.
El sabotaje económico motivado políticamente y desatado por Fedecámaras demuestra la conciencia de clase de la burguesía; la "burguesía emergente" ha penetrado el aparato del Estado.

Critica los vínculos del Gobierno con el sector empresarial y la ausencia de chavistas radicales en el Gobierno.

El viejo Estado venezolano, a pesar de ser controlado por socialistas, no puede romper el dominio de la estructura capitalista. Es necesario que las estructuras paralelas desplacen a las estructuras existentes, incluyendo las del viejo Estado.

Fuente: Elaboración propia.

Algunos analistas y activistas que representan diferentes corrientes y tradiciones izquierdistas se aproximan al instrumentalismo centrándose en los compromisos personales e ideológicos de quienes están en el poder y la penetración del Estado venezolano por representantes del viejo orden. La con- 
vergencia de estos izquierdistas provenientes de diversas tradiciones pone en evidencia la relevancia del instrumentalismo, incluso en su versión simplista o dogmática, para estructurar temas que están en el centro del debate en la Venezuela chavista. Algunos de estos izquierdistas alcanzaron prominencia en distintos momentos de la presidencia chavista, como Alan Woods, un miembro destacado de la Tendencia Marxista Internacional (TMI) trotskista, quien fue asesor de Chávez; el exviceministro de Planificación y activista de movimientos sociales Roland Denis; el renombrado intelectual de larga trayectoria y exlíder político Domingo Alberto Rangel (quien fue uno de los primeros en usar el término "boliburguesía", en el 2006); y, más recientemente, el exguerrillero y columnista Toby Valderrama. Tanto Woods como Denis descartaron la transformación del Estado venezolano existente y en cambio defendieron la estrategia de poder dual asociada con Lenin, en la que nuevas instituciones independientes como las "misiones" de educación y las milicias remplazarían al sistema escolar establecido y las Fuerzas Armadas respectivamente. Del mismo modo, las instituciones "representativas" como los gobiernos municipales eventualmente serían desplazadas por el "poder del pueblo" (tal como lo encarna los consejos comunales y las comunas), en contraste con el modelo defendido por los chavistas moderados que favorecen la coexistencia de la democracia representativa y "participativa".

Woods y sus seguidores trotskistas venezolanos se adhirieron a la visión instrumentalista al argumentar que el Estado venezolano estaba estrechamente ligado a la estructura capitalista y fue penetrado "en todos los niveles" por "contrarrevolucionarios"; el Estado, lejos de ser un vehículo para un cambio de gran alcance, tendría que ser eventualmente remplazado (Woods, 2008, p. 415; ver también, Valderrama y Mena, 2005, p. 69). En consonancia con el instrumentalismo (ver tabla 1), Woods consideraba que la "revolución" consistía en grandes rupturas radicales y definitivas con el pasado, como la expropiación de la banca y grandes fincas agrícolas durante un periodo relativamente corto. Woods junto con la exfilial venezolana de la TMI, la Corriente Marxista Revolucionaria (CMR, que en el 2010 se separó como parte de un cisma trotskista internacional), argumentaron que casi todos los gerentes estatales y la burocracia del Estado en general "pelearían con las uñas y los dientes para mantener la lucha dentro del marco capitalista" (CMR, 2013, p. 3). Woods también señaló que los miembros de las tendencias chavistas de izquierda (que incluían a Eduardo Samán, quien fue removido dos veces de su posición gubernamental) y Luis Tascón (a quien se le negó el ingreso en el 
PSUV) estaban en gran parte ausentes de los altos cargos gubernamentales. Sin embargo, a diferencia del "instrumentalismo duro" al que se adhirieron otros trotskistas, Woods y sus seguidores venezolanos se abstuvieron de plantear que el liderazgo chavista y el mismo Gobierno eran representantes del sistema capitalista y, en cambio, señalaron a los "burócratas" del Estado como una fuente principal de resistencia a la transformación verdadera. En ese sentido, el análisis de Woods fue menos rígido o dogmático que otros grupos trotskistas, que clasificaron al Gobierno chavista como "burgués" y que fueron acusados por Woods (2009, pp. 12-14; 2008, pp. 391-392) de defender posiciones "ultraizquierdistas". ${ }^{13}$

El análisis de Woods se caracterizó por un enfoque personalista, que fue también el caso con los escritores instrumentalistas criticados por Poulantzas en su debate con Miliband. Woods veía a Chávez como virtualmente solo entre los principales líderes chavistas en su demostración de tenacidad política y le dio todo el crédito por los avances de su Gobierno, sin referirse al papel positivo que pudiera haber desempeñado otros líderes políticos o miembros de su gabinete. La CMR (2013, p. 2) articuló esta perspectiva con referencia a Chávez: "El coraje, la fuerza de carácter y la determinación de los líderes juegan un papel importante en la historia, y en momentos críticos, pueden ser decisivos para el proceso revolucionario".

Los que se adhirieron a la perspectiva instrumentalista aplicaron dos conceptos a la política venezolana bajo Chávez. Roland Denis, que escribe en la tradición libertaria, argumentó que el "poder constituido" (formado por los burócratas, los líderes del PSUV y otros miembros de la clase gobernante) estaba enfrentado a los sectores populares organizados, o el "poder constituyente", y representaba el verdadero obstáculo al cambio en Venezuela. Toby Valderrama, cuya formación política estaba más en concordancia con el marxismo ortodoxo, llamó a una "revolución en la revolución", un término usado ocasionalmente por Chávez y Maduro pero que reflejaba el pensamiento de los chavistas radicales. Ambos conceptos implicaban que el enemigo era claramente identificable y se encontraba dentro del movimiento. La noción de "poder constituido-poder constituyente" y, aunque en menor medida, el concepto de la "revolución en la revolución" reflejan una visión polarizada típica

13 De la misma manera que negó que el Gobierno venezolano era "burgués", Woods y la TMI rechazaron la tesis — que había sido siempre la fuente de controversia entre fracciones trotskistas — de que la Unión Soviética bajo Stalin había restaurado el capitalismo (Woods, 2008, pp. 260-263). 
del pensamiento instrumentalista, en la que están trazadas, con claridad, las líneas entre revolucionarios y contrarrevolucionarios.

En el contexto de la política europea y estadounidense de la década de 1960 y 1970, la línea de pensamiento instrumentalista — con su afirmación de que la influencia continua y directa de los capitalistas sobre los políticos en el poder supera con creces a la de los sectores populares - se oponía a las alianzas izquierdistas con los moderados políticos que estaban cerca de los asientos del poder. En el contexto de la Venezuela chavista, la visión instrumentalista de los tentáculos perniciosos de la clase capitalista, que penetran la esfera política, condujo a conclusiones similares. Como indica la tabla 1, la perspectiva instrumentalista se prestó a una posición crítica sobre el llamado a alianzas con los empresarios, formulado tanto por Chávez como por Maduro (ver, por ejemplo, Bilbao, 2008, pp. 182, 195-196).

\subsection{El enfoque marxista estructural}

El pensamiento marxista estructural se prestó al apoyo de alianzas tácticas con el sector empresarial propuesto por Chávez y Maduro. El acuerdo "táctico" fue diseñado para estimular la producción con el fin de superar la escasez. Tal objetivo era más modesto que la "revolución democrática nacional" basada en una "alianza estratégica" que incorporaba la clase obrera y la burguesía nacional, promovida por los izquierdistas latinoamericanos del siglo pasado con el objetivo de alcanzar la independencia económica y lograr otras metas ambiciosas. Los líderes y analistas chavistas que pertenecen a una corriente moderada dentro del movimiento, que atribuían la escasez y los problemas económicos relacionados principalmente a las distorsiones del mercado (como se discutió antes), tendieron a apoyar las negociaciones con el sector privado para llegar a acuerdos de naturaleza táctica en favor de soluciones prácticas tomando en cuenta las exigencias del mercado. La misma combinación de análisis basada en la lógica económica del capitalismo (en oposición a las maquinaciones de los capitalistas), junto con el apoyo a las alianzas tácticas con los izquierdistas moderados, había también caracterizado a los marxistas estructurales como Althusser en la década de 1970. 


\section{Tabla 2}

LAS POSICIONES DE LA TEORÍA DEL MARXISMO ESTRUCTURALISTA SOBRE TEMAS CRÍTICOS EN DOS CONTEXTOS DISTINTOS

\begin{tabular}{|c|c|c|}
\hline Tres temas críticos & $\begin{array}{l}\text { Posiciones izquierdistas en las } \\
\text { naciones desarrolladas bajo } \\
\text { circunstancias normales }\end{array}$ & $\begin{array}{c}\text { Posiciones izquierdistas en la } \\
\text { Venezuela chavista }\end{array}$ \\
\hline $\begin{array}{l}\text { Tema 1: } \\
\text { Conciencia } \\
\text { de clase de la } \\
\text { burguesía o } \\
\text { sectores de ella }\end{array}$ & $\begin{array}{l}\text { La burguesía tiene poca conciencia } \\
\text { de clase, ya que sus intereses corpo- } \\
\text { rativistas eclipsan los asuntos sisté- } \\
\text { micos a largo plazo. }\end{array}$ & \\
\hline $\begin{array}{l}\text { Tema 2: } \\
\text { Formación de } \\
\text { alianzas }\end{array}$ & $\begin{array}{l}\text { Apoya las alianzas tácticas (en con- } \\
\text { traste con las alianzas estratégicas) } \\
\text { con la clase media progresista y con } \\
\text { los partidos social demócratas con } \\
\text { vínculos en los asientos del poder. }\end{array}$ & $\begin{array}{l}\text { Favorece las "alianzas tácticas" con } \\
\text { la burguesía "productiva" emergen- } \\
\text { te, para alcanzar un modus vivendi. } \\
\text { Descarta los "pactos" (en efecto } \\
\text { "alianzas estratégicas") con los mo- } \\
\text { derados. }\end{array}$ \\
\hline $\begin{array}{l}\text { Tema 3: } \\
\text { Naturaleza de } \\
\text { la transición al } \\
\text { socialismo }\end{array}$ & & $\begin{array}{l}\text { Centran sus esfuerzos en la consoli- } \\
\text { dación de los logros existentes para } \\
\text { mantener la estabilidad. }\end{array}$ \\
\hline
\end{tabular}

Fuente: Elaboración propia.

La propuesta de un entendimiento formal o una alianza con los empresarios productivos, que fue ocasionalmente formulada por Chávez, se convirtió en un objetivo fundamental del Gobierno de Maduro en el contexto de la violencia callejera que sacudió a Venezuela a partir de febrero del 2014. Al mismo tiempo que el Gobierno acusó a los capitalistas venezolanos de llevar a cabo sabotaje económico, también los invitó a establecer un diálogo e hizo énfasis en la necesidad de la cooperación entre el Estado y el sector privado.

El Gobierno de Maduro previó lo que este artículo ha llamado una "relación táctica" con el sector privado. El término "táctico" en vez de "estratégico" es apropiado por varias razones. En primer lugar, la burguesía emergente no logró cumplir las expectativas de los líderes chavistas debido su pobre desempeño productivo, que desacreditó la propuesta de una alianza sólida y duradera entre el Gobierno y los miembros del sector empresarial. En segundo lugar, una de las piedras angulares del discurso de Chávez sobre la democracia venezolana pos-1958 fue el rechazo a la "democracia pactada", que había reunido a los miembros de las élites de la nación para definir las políticas básicas, pero dejó al margen a los sectores populares. Los líderes 
chavistas negaron firmemente que las negociaciones con el sector privado representaran un "pacto" y en cambio insistieron en que estaban tratando de llegar a "acuerdos" (Arreaza, 2013). En este contexto, un "pacto" puede considerarse equivalente a una "alianza estratégica" para lograr objetivos a largo plazo, mientras que los llamados "acuerdos" eran de naturaleza "táctica". ${ }^{14}$

Otro aspecto del marxismo estructural aplicado a Venezuela es que la función del Estado es preservar la estabilidad -y, por lo tanto, la priorización de la consolidación-. En este sentido, el cambio se lleva a cabo en forma de etapas en vez de un "proceso" que gradualmente conduce al socialismo. El marxismo estructural prevé un Estado suficientemente independiente de los intereses inmediatos de los capitalistas como para poder implementar importantes reformas populares. Al mismo tiempo, los chavistas, influenciados por el marxismo estructural, se quedaron cortos ante la visión de Poulantzas II de un Estado que está en constante cambio. El Estado puede así apartarse de la estructura capitalista, pero bajo circunstancias normales no puede romper con ella. Eventualmente, cuando las condiciones objetivas y subjetivas alcancen un cierto nivel, se producirá una gran ruptura revolucionaria, pero hasta entonces lo mejor que se puede esperar es la consolidación de los logros en un periodo de paz. Los chavistas moderados defendieron esta línea de pensamiento frente a las tácticas violentas empleadas por la oposición después de la muerte de Chávez, argumentando que la principal tarea del Gobierno era defender los logros de los últimos quince años. Este enfoque defensivo basado en etapas descartó la radicalización continua o, en las palabras de los trotskistas, una "revolución permanente".

\subsection{El enfoque de Poulantzas II}

El tercer enfoque dentro del chavismo contrastaba con los otros dos: el enfoque instrumentalista, que veía al Estado venezolano como demasiado monolítico y atado a la estructura capitalista para ser modificable; y el enfoque marxista estructural, que sostenía que el Gobierno no tenía más remedio que

14 Temir Porras, director de varias importantes instituciones financieras del Estado, propuso lo que este artículo define como una "alianza estratégica" con el sector privado. Porras argumentaba que el trato preferencial hacia la burguesía venezolana, por encima del capital transnacional, aumentaría la producción nacional y permitiría al Gobierno consolidar los logros aun cuando no avanzara hacia el socialismo. Además, recomendó a Maduro que rechazara el liderazgo colectivo como había hecho Chávez, y que siguiera una "estrategia pragmática" de ganar a la clase media para incrementar el apoyo electoral chavista a niveles muy por encima del $50 \%$. Porras, cuyas propuestas generaron controversia dentro del movimiento chavista, fue removido de sus cargos a finales del 2013. 
respetar la lógica del capitalismo y apoyaba las alianzas tácticas con el sector privado para consolidar los logros pasados hasta que las condiciones permitieran iniciar una etapa más radical. El tercer enfoque se aproximaba al pensamiento de Poulantzas II, que negaba la capacidad del Estado por sí mismo de romper con las estructuras capitalistas y lo vio como una reflexión de la correlación de las fuerzas políticas y sociales en el país. Como en el caso de Poulantzas II, el tercer enfoque atribuía igual importancia a la lucha fuera del Estado y una guerra de posición dentro de él con el fin de lograr una transformación radical.

\section{Tabla 3}

Las Posiciones de Poulantzas II sobre temas Críticos en dos Contextos distintos

\begin{tabular}{ccc}
\hline Tres temas críticos & $\begin{array}{c}\text { Posiciones izquierdistas en las } \\
\text { naciones desarrolladas bajo } \\
\text { circunstancias normales }\end{array}$ & $\begin{array}{c}\text { Posiciones izquierdistas en la } \\
\text { Venezuela chavista después de } \\
1998\end{array}$ \\
\hline
\end{tabular}

Tema 1: Conciencia La burguesía carece de cohesión, de clase de la burguesía o sectores de ella está altamente fragmentada y es internamente inestable. está altamente fragmentada y es internamente inestable, características que favorecen la posibilidad de un cambio de gran alcance.

Una correlación favorable de fuerzas en la sociedad obvia la necesidad de alianzas con los no izquierdistas.
Tema 2: Formación de alianzas

Tema 3: Naturaleza de la transición al socialismo
Apoya las alianzas estratégicas con la "clase media progresista", como también con los partidos socialdemócratas con vínculos en la más alta esfera de poder.

Los revolucionarios pueden hacerse cargo del Estado para transformarlo (en vez de destruirlo). La revolución consiste en una serie de "rupturas reales" con el pasado durante un periodo extendido en contraste con la idea de "un gran día".
Prevé un "proceso" revolucionario continuo (o multiplicidad de rupturas) caracterizado por la transformación continua del Estado en el contexto de la aguda polarización y conflicto político y social.

Fuente: Elaboración propia,

Marta Harnecker, exalumna de Althusser, quien a veces se reunía con Chávez y cuyos escritos fueron un punto de referencia para quienes apoyaron la posición de Poulantzas II en Venezuela, defendió la estrategia de trabajar simultáneamente dentro y fuera del Estado. Según ella, las funciones administrativas del "Estado heredado [...] son asumidas por cuadros revolucionarios quienes lo utilizan para impulsar el proceso de cambio" que apunta hacia la creación 
de un nuevo Estado que "empieza a nacer desde abajo, a través del ejercicio del poder popular en varias instituciones, incluidos los consejos comunales". Harnecker etiquetó este proceso como algo único por cuanto "el Estado heredado fomenta el surgimiento del nuevo Estado que lo reemplazará". Ella 1lamó a esta relación "complementaria" en vez de "una en la que los dos Estados se niegan mutuamente" (en una referencia indirecta a Lenin). Por esta razón, "el movimiento organizado debe [...] ejercer presión sobre el Estado heredado" (Harnecker, 2010, p. 62; ver también, Harnecker, 2012, pp. 166-167; Lebowitz, 2010, p. 152-153; Bilbao, 2008, p. 195). La visión de Harnecker es apoyada por aquellos chavistas que aceptan la coexistencia del modelo de "la democracia electoral" (a pesar de que es generalmente condenado por los chavistas izquierdistas por encarnar el viejo sistema dominado por la élite) y "la democracia participativa" (asociada con el nuevo Estado).

El concepto chavista de "proceso de cambio" es compatible con la visión de la revolución de Poulantzas II consistente de una serie de "rupturas reales" durante un periodo prolongado de tiempo, en contraposición con la visión ortodoxa izquierdista de la revolución como una toma del poder de un solo tiro. El "proceso de cambio" como un desarrollo continuo de las transformaciones estructurales también contrasta con la visión de etapa más estática inherente al pensamiento del marxismo estructural, como se discutió antes, que Poulantzas II rechazó (Poulantzas, 1979, p. 196). También contrasta con la posición eurocomunista representada por el secretario general del Partido Comunista español Santiago Carrillo, la cual Poulantzas (1979, p. 196), como partidario de una facción izquierdista del eurocomunismo, calificó de "eurocomunismo de derecha". Carrillo (1977), a diferencia de Poulantzas, minimizó la lucha social y el conflicto en el periodo anterior al logro del socialismo.

Finalmente, la visión de "rupturas reales" de Poulantzas contrastaba con el "reformismo" que, como señalan los teóricos políticos argentinos Mabel Thwaites Rey y Hernán Ouviña, no asegura los cambios estructurales implícitos en el término "transición" (o el término chavista "proceso"). Thwaites Rey y Ouviña (2012, pp. 75-78) añaden que el reformismo, en contraste con la transición (tal como previó Poulantzas), está dirigido principalmente desde el Estado y no por las bases, y sus líderes carecen de visión a largo plazo, o compromiso con el cambio radical.

Los chavistas que se adhirieron a la línea de pensamiento de Poulantzas II estaban convencidos de que las condiciones subjetivas favorables en Venezuela (como resaltaba el discurso de Chávez), así como la fragmenta- 
ción de la burguesía (que Poulantzas había subrayado) y su pérdida de prestigio, hacían posible una radicalización progresiva y, por lo tanto, se evitaba la necesidad de depender de la fuerza (Gates, 2010, pp. 26-31; Ortiz, 2004, pp. 79-81). Esta posición relativamente optimista descartaba las alianzas de cualquier tipo con los sectores empresariales y los no izquierdistas en general. La corriente chavista que se aproximaba a Poulantzas II contemplaba un proceso continuo de profundización del cambio caracterizado por pequeñas rupturas (como el lanzamiento de los consejos comunales y las comunas), en lugar de rupturas más radicales (como las expropiaciones masivas y la "revolución en la revolución") en un periodo de tiempo más corto de acuerdo con el pensamiento instrumentalista. En resumen, las dos características siguientes de Venezuela en la era de Chávez explican la relevancia de Poulantzas II: el optimismo (tal como lo expresa el discurso de Chávez) y al mismo tiempo el reconocimiento de que el socialismo se alcanzará durante un periodo prolongado; y la lucha política continua en el contexto de la aguda polarización social y política.

\section{Conclusión}

Después de un vacío de varias décadas, se ha revivido el interés en el debate marxista sobre el Estado de la década de 1960 y 1970, en parte como consecuencia de las experiencias de los recientes gobiernos latinoamericanos comprometidos con el socialismo democrático. La cuestión fundamental planteada por los teóricos marxistas hace medio siglo está todavía en el centro de la discusión: dada la premisa básica del marxismo de que existe un nexo entre la estructura capitalista y la superestructura del Estado, ¿en qué circunstancias puede el Estado distanciarse de la influencia de la estructura y separarse eventualmente de ella?

La aplicación de las tres teorías marxistas a una situación como la de Venezuela de intensa polarización y radicalización en un contexto democrático es diferente de situaciones en las que los moderados desempeñan el papel dominante a favor del cambio y, al mismo tiempo, las perspectivas para el socialismo son percibidas como menos prometedoras. Sin embargo, en ambos conjuntos de circunstancias, el marxismo estructural ha sido compatible con las alianzas entre los izquierdistas y no izquierdistas. En contraste, el pensamiento de Poulantzas II, que era incluso más partidario de las alianzas (o 
lo que este artículo llama "alianzas estratégicas") en la Europa de la década de 1970, era compatible con una estrategia de profundización continua del proceso de cambio promovido por los chavistas, en vez de concesiones a los grupos ubicados a su derecha. La estrategia de Poulantzas II en Venezuela, sin embargo, no llegó al extremo de apoyar las rupturas radicales y abruptas defendidas por corrientes (como el trotskismo) que están más a la izquierda.

Las explicaciones marxistas instrumentalistas y estructurales de los problemas económicos apremiantes a los que se enfrenta la presidencia de Maduro tienen en ambos casos un grado de aplicabilidad, y no son necesaria ni mutuamente excluyentes. El instrumentalismo aplicado a Venezuela se centraría en dos expresiones del poder de la burguesía que frenaron el proceso de cambio. En primer lugar, los grupos económicos tradicionales representados por Fedecámaras han seguido sistemática y conscientemente políticas de producción e inversión (o desinversión) destinadas a generar graves dificultades económicas para preparar el terreno para el "cambio de régimen”. En segundo lugar, la llamada "boliburguesía" constituida por grupos empresariales emergentes ha penetrado la esfera gobernante y, de este modo, impide o incluso revierte la construcción socialista. En ambos casos, la burguesía o fracciones de esa clase desempeñaron un papel directo en la política.

En contraste, el marxismo estructural aplicado a Venezuela atribuiría los problemas económicos de la nación a la lógica del mercado. De acuerdo con esta explicación, el Gobierno se alejó demasiado de la economía de mercado ya que la disparidad entre los precios regulados y los tipos de cambios oficiales, por un lado, y los precios del mercado libre, por el otro, alcanzó extremos sin precedentes.

En otras partes del mundo, la tesis del instrumentalismo ha sido más convincente en las situaciones de "capitalismo de compinches" y neoliberalismo en el que grupos económicos poderosos ejercen una influencia directa sobre la toma de decisiones del Estado. El instrumentalismo parece ser menos aplicable para el caso de los gobiernos bonapartistas y socialdemócratas (como el Gobierno laborista de la posguerra) y en la Alemania nazi que se caracterizaron por una mayor autonomía estatal. Venezuela pareciera asemejarse al bonapartismo, dada la desconexión entre la estructura capitalista dominante de la nación y el compromiso socialista del Gobierno. Sin embargo, como este artículo demuestra, los sectores empresariales desarrollaron vínculos estrechos con el movimiento y el Gobierno chavista según lo previsto por los instrumentalistas. 
El punto de vista de Poulantzas II sobre la transformación del Estado que abre el camino al socialismo también es aplicable al caso de Venezuela. Algunos teóricos marxistas señalan la experiencia chavista en Venezuela como evidencia de que el socialismo representa un periodo de transición propenso a las contradicciones extremas y al agudo conflicto político y social (Sader, 2011, p. 138; Lebowitz, 2010, pp. 105-109; Raby, 2006, p. 262). La visión del socialismo como un sistema en constante flujo es compatible con la teoría de Poulantzas II que el Estado está sujeto a profundas contradicciones internas y constituye un campo estratégico que refleja la correlación de fuerzas políticas en un momento dado, y como tal, es intrínsecamente inestable (Jessop, 1982, pp. 157-158). Si el concepto de "campo de batalla estratégico" es particularmente aplicable en un periodo de gradual ascendencia izquierdista, que Poulantzas esperaba ocurriera en Europa en la década de 1970, es aún más pertinente en un contexto como Venezuela bajo el Gobierno chavista. Venezuela a principios del siglo XXI se caracterizó por la transformación y la inestabilidad, como resultado de una intensa polarización social y política con un Gobierno que estaba comprometido con el socialismo a través de la lucha, y la existencia de una estructura capitalista que solo fue parcialmente debilitada por las incursiones izquierdistas, todas las cuales conformaron un cuadro conducente a la inestabilidad. Aquellos chavistas que favorecían la radicalización progresiva en medio de la inestabilidad, tal como se plasmó en el eslogan "el proceso de cambio", rechazaban en efecto una visión de etapas basada en la consolidación de los logros y la priorización de la estabilidad relativa.

Las tres líneas de pensamiento como explicaciones de los dilemas que confrontan los gobiernos chavistas son todas convincentes. El papel directo y consciente del sector privado (como lo destacaron los instrumentalistas) creó obstáculos para la transformación de gran alcance. En concordancia con el instrumentalismo, evidencia considerable indica que la escasez fue inducida por razones políticas. Se inició con la huelga general promovida por Fedecámaras en el 2002-2003, que a su vez obligó al Gobierno a adoptar dos estrategias que frenaron el avance del socialismo. En primer lugar, el Gobierno se enfrentó a la amenaza de su propia supervivencia mediante la adopción de medidas populistas, que incluyeron el mantenimiento de una cierta disparidad entre los precios regulados y los del mercado. La política funcionó bien al principio, pero finalmente produjo perturbaciones económicas que disminuyeron el apoyo al Gobierno y lo colocaron a la defensiva. En segundo lugar, el tratamiento preferencial del Gobierno hacia una burguesía emergente que 
se negó a acompañar las acciones desestabilizadoras de Fedecámaras condujo a la penetración empresarial de las esferas gobernantes (según lo previsto por el instrumentalismo) y en algunos casos a la corrupción.

Además, más allá de las acciones planificadas de los capitalistas en el frente económico y otros acontecimientos en Venezuela que encajan en el marco analítico instrumentalista, la lógica económica del capitalismo estaba en juego de acuerdo con el marxismo estructural. En un momento dado, los capitalistas podían haberse retirado completamente de la política, pero las perturbaciones del mercado creadas por sus acciones originales habrían continuado sin cesar, particularmente porque los líderes chavistas no lograron tomar el mercado suficientemente en serio. Poulantzas II también arroja luz sobre la relación entre la estructura y la superestructura en el contexto venezolano. Dada la inestabilidad estimulada por una oposición desleal que cuestionaba la legitimidad del Gobierno, cualquier cambio en la correlación de las fuerzas políticas en la nación tenía un marcado impacto en la configuración de las tendencias ideológicas dentro del Estado, como lo propuesto por Poulantzas II.

Una apreciación de la naturaleza compleja de los temas teóricos y prácticos discutidos en este artículo sirve para contrarrestar la desilusión en las filas chavistas que proviene de un proceso de cambio tan largo en el contexto de una confrontación intensa y de privaciones materiales, junto con notorios casos de corrupción. La complejidad del concepto marxista de estructura-superestructura, los desafíos de una estrategia de la radicalización en un entorno democrático y las circunstancias que rodean la decisión de promover la burguesía no tradicional ciertamente no justifican la corrupción, las inconsistencias y los errores en las políticas. Sin embargo, ayudan a ubicar los problemas en un contexto más amplio y contrarrestar la noción de que el liderazgo chavista sea simplemente incompetente o se ha vendido.

El artículo pone en evidencia esta complejidad, tanto en el frente empírico como el teórico, al demostrar que las exigencias del mercado, así como la presión política y las perturbaciones generadas por los capitalistas, desempeñaron papeles importantes. Las opciones del Gobierno fueron limitadas como resultado de la resistencia política y económica de los empresarios, pero también como consecuencia de la amplia disparidad entre los precios regulados y los oficiales, que el Gobierno de Maduro no logró contener. De manera similar, el artículo sugiere que el término "en última instancia", usado por los teóricos marxistas del Estado como Althusser y Poulantzas, se hace algo 
obscuro al tratar de determinar si la lógica del capitalismo o la presión e influencia ejercida por los capitalistas es el factor fundamental.

Otro corolario del enfoque estructural es que el punto de partida para afrontar los desafíos en la transición del capitalismo debería ser un partido de izquierda democráticamente estructurado y apoyado por fuertes movimientos sociales. A diferencia del Estado, un partido verdaderamente revolucionario es independiente en gran parte de la estructura capitalista durante el periodo de construcción socialista. Su condición semiautónoma es reforzada por fuertes movimientos sociales que también ejercen influencia sobre el Estado. Más que los izquierdistas en el Gobierno, el partido izquierdista es capaz de frenar la ineficiencia y la corrupción de la burocracia estatal. Como afirmó Poulantzas II, al mismo tiempo que los izquierdistas hacen una guerra de posición dentro del viejo Estado, tienen que organizarse y movilizarse fuera e independiente de él (Jessop, 2008, p. 118; Poulantzas, 1978, p. 251). Mientras que rechazaba la tesis del poder dual de Lenin y la autonomía absoluta del paradigma de "nuevo movimiento social", Poulantzas (1978, p. 141) insistió en que las luchas populares "siempre tienen efectos a largo plazo dentro del Estado" (además, ver Jessop, 1982, p. 179).

En este sentido, los chavistas han tenido un récord mixto. En el lado negativo, el PSUV es en gran parte controlado por los ministros, gobernadores, alcaldes y otros chavistas que forman parte del Estado. Para su crédito, los chavistas han celebrado numerosas primarias internas que, a pesar de la distribución desigual de recursos entre los candidatos, es un mecanismo eficaz para facilitar la expresión del sentimiento de las bases. Chávez entendió la necesidad de aprovechar el entusiasmo de las bases al brindarles oportunidades fuera del ámbito electoral para participar en la toma de decisiones. Uno de sus últimos esfuerzos en este sentido fue la creación del Gran Polo Patriótico en el 2011 que incorporó los movimientos sociales y los partidos aliados como el Partido Comunista (PCV) y otros que estaban a la izquierda del PSUV pero que mantuvieron una posición de apoyo crítico al Gobierno. En contraste, Maduro está menos inclinado a aceptar las críticas de los que están fuera del círculo del poder. Las corrientes chavistas izquierdistas, por ejemplo, objetaron la participación de los superdelegados, principalmente funcionarios chavistas electos, en el Tercer Congreso del PSUV celebrado en julio del 2011, y que representaba casi el $40 \%$ de todos los delegados. Además, el PSUV se abstuvo de convocar elecciones primarias para escoger sus candidatos gubernamentales para las elecciones del octubre y diciembre del 2017. 
Desde el momento inicial de la primera presidencia de Chávez en 1999, los chavistas aprovecharon su dominio del poder político y decretaron medidas desde arriba para profundizar el proceso de cambio. El Gobierno chavista desempeñó un papel fundamental en la organización y movilización de los sectores populares y al mismo tiempo incentivó un sentido de empoderamiento entre ellos. Así fue el caso del lanzamiento de los consejos comunales que proliferaron después del 2006.

Estos esfuerzos, sin embargo, no pueden considerarse suficientes para alcanzar los objetivos a largo plazo que fueron formulados en favor de la transformación estructural. La experiencia chavista en Venezuela confirma lo que estaba implícito en casi todos los escritos marxistas sobre el Estado, y explícito en Poulantzas II. En una nación capitalista no importa cuán bien intencionados sean los revolucionarios en el poder, la movilización desde afuera del Estado y relativamente independiente de él es una condición sine qua non para la profundización continua del proceso de cambio que apunta en la dirección del socialismo. 


\section{Bibliografía}

Althusser, L. (2014[1995]). On the Reproduction of Capitalism: Ideology and the Ideological State Apparatuses. Verso: Londres.

Althusser, L. (1971). Lenin and Philosophy and Other Essays. Nueva York: Monthly Review Press.

Althusser, L. y Balibar, E. (1970). Reading “Capital”. Londres: Verso.

Arreaza, J. (2016). Entrevista con el exvicepresidente de Venezuela (25 de enero). Barcelona.

Barrow, C. W. (1993). Critical Theories of the State: Marxist, Neo-Marxist, Post-Marxist. Wisconsin: University of Wisconsin.

Bilbao, L. (2008). Venezuela en revolución: el renacimiento del socialismo. Buenos Aires: Ediciones Le Monde.

Block, F. (1980). Beyond relative autonomy: state managers as historical subjects. Socialist Register, 17, pp. 227-242.

Block, F. (1977). The ruling class does not rule: notes on the marxist theory of the state. Socialist Revolution, 33, pp. 7-28.

Carrillo, S. (1977). Eurocommunism and the State. Londres: Lawrence and Wishart.

Coronil, F. (2002). El estado mágico: naturaleza, dinero y modernidad en Venezuela. Caracas: Nueva Sociedad.

CMR [Corriente Marxista Revolucionaria] (2013). El legado de Hugo Chávez: la revolución venezolana y la lucha por el socialismo. El Militante (abril), pp. 1-4.

Collier, R. B. y Collier, D. (1991). Shaping the Political Arena: Critical Junctures, the Labor Movement, and Regime Dynamics in Latin America. Princeton: Princeton University Press.

Domhoff, G. W. (1990). The Power Elite and the State: How Policy is Made in America. Nueva York: Aldine de Gruyter.

Ellner, S. (2014). El fenómeno Chávez: sus orígenes y su impacto (hasta 2013). Caracas: CELARG.

Ellner, S. (1980). Los partidos politicos y su disputa por el control del movimiento sindical en Venezuela, 1936-1948. Caracas: Universidad Católica Andrés Bello.

Ferreter, L. (2006). Louis Althusser. Londres: Routledge.

Gates, L. C. (2010). Electing Chavez: The Business of Anti-Neoliberal Politics in Venezuela. Pittsburgh: University of Pittsburgh Press.

Harnecker, M. (2012). Why Socialism? Science and Society, 76 (2), pp. 163-167.

Harnecker, M. (2010). Latin America and Twenty-First Century Socialism: Inventing to Avoid Mistakes. Monthly Review, 62(3), pp. 3-83. 
Healey, D. R. [entrevistada por Maurice Isserman] (1993). California Red: A Life in the American Communist Party. Illinois: University of Illinois Press.

Hedges, C. (2010). Death of the Liberal Class. Nueva York: Nation Books.

Isserman, M. (1987). If I Had a Hammer... The Death of the Old Left and the Birth of the New Left. Nueva York: Basic Books.

Jessop, B. (2008). A Strategic Relational Approach. Cambridge: Polity Press.

Jessop, B. (2002). The politics of representation and the Eighteenth Brumaire. En M. Cowling y J. Martin (Eds.). The Eighteenth Brumaire Today. Londres: Pluto Press.

Jessop, B. (1982). The Capitalist State: Marxist Theory and Methods. Oxford: Martin Robertson.

Katz, C. (2015). Dualities of Latin America. Latin American Perspectives, 42(4), pp. 10-42.

Lebowitz, M. A. (2010). The Socialist Alternative: Real Human Development. Nueva York: Monthly Review Press.

Lewis, W. S. (2007). Editorial introduction to Louis Althussers letter to the Central Committee of the PCF, 18 March 1966. Historical Materialism, 15(2), pp. 133-151.

Lundberg, F. (1969). The Rich and the Super-Rich: A Study in the Power of Money Today. Nueva York: Banton Books.

Miliband, R. (1977). Marxism and Politics. Oxford: Oxford University Press.

Miliband, R. (1969). The State in Capitalist Society: An Analysis of the Western System of Power. Nueva York: Basic Books.

Mills, C. W. (1956). The Power Elite. Nueva York: Oxford University Press.

Miquilena, L. (2000). Entrevista (8 de febrero). Caracas. Recuperado de: http://lists.csbs. utah.edu/pipermail/marxism/2000-August/041693.html.

Morales, A. (2004). Entrevista con la directora de la formación ideológica del partido MVR (30 de marzo). Caracas.

Müller, J. (2009). Artículo de reseña de "Poulantzas lessen: Zur Aktualität marxistischer Staatshtheorie". Historical Materialism, 17(4), pp. 143-155.

Ortiz, N. (2004). Entrepreneurs: profits without power? En J. McCoy y D. J. Myers (Eds.). The Unraveling of Representative Democracy in Venezuela. Baltimore: Johns Hopkins University Press.

Poulantzas, N. (1979). Interview with Nicos Poulantzas. Marxism Today, 23(7), pp. 194-201.

Poulantzas, N. (1978). State, Power, Socialism. Londres: New Left Books.

Poulantzas, N. (1975). Classes in Contemporary Capitalism. Londres: New Left Books.

Poulantzas, N. (1969). The problem of the capitalist state. New Left Review, 58, pp. 67-78. 
Raby, D. L. (2006). Democracy and Revolution: Latin America and Socialism Today. Londres: Pluto Press.

Rangel, D. A. (2006). La boliburguesía. Correo del Caroní (20 de abril).

Sader, E. (2011). The New Mole: Paths of the Latin American Left. Londres: Verso Books.

Schemel, O. (2014). Entrevista, programa José Vicente Hoy (27 de julio). Televen.

Seymour, R. (2012). Terrifyingly real: Poulantzas and the capitalist state. Lenin's Tomb (25 de enero). Recuperado de: http://www.leninology.com/2012/01/terrifyingly-realpoulantzas-and.html.

Sweezy, P. (1942). The Theory of Capitalist Development: Principles of Marxian Political Economy. Nueva York: Monthly Review.

Thwaites Rey, M. y Ouviña, H. (2012). La estabilidad latinoamericana revisitada: reflexiones e hipótesis alrededor del problema del poder política y las transiciones. En M. Thwaites Rey (Ed.). El Estado en América Latina: continuidades y rupturas. Buenos Aires: CLACSO.

Valderrama, T. y Mena, A. (2005). Rumbo al socialismo. Barcelona: Editorial Fabricio Ojeda.

Woods, A. (2009). Prólogo: Inveval cómo los trabajadores pueden dirigir la sociedad. En P. Cormenzana (Ed.). La batalla de Inveval: La lucha por el control obrero en Venezuela. Madrid: Fundación Federico Engels.

Woods, A. (2008). Reformismo o revolución: marxismo y socialismo del siglo XXIRespuesta a Heinz Dieterich. Madrid: Fundación Federico Engels. 